University of Nebraska - Lincoln

DigitalCommons@University of Nebraska - Lincoln

US Department of Energy Publications

U.S. Department of Energy

2002

Sorption of Cs+ to micaceous subsurface sediments from the

Hanford site, USA

John M. Zachara

Pacific Northwest National Laboratory, john.zachara@pnl.gov

Steven Smith

Pacific Northwest National Laboratory, steven.smith@pnl.gov

Chongxuan Liu

Pacific Northwest National Laboratory, chongxuan.liu@pnl.gov

James Mckinley

Pacific Northwest National Laboratory, james.mckinley@pnl.gov

R. Jeffrey Serne

Pacific Northwest National Laboratory

See next page for additional authors

Follow this and additional works at: https://digitalcommons.unl.edu/usdoepub

Part of the Bioresource and Agricultural Engineering Commons

Zachara, John M.; Smith, Steven; Liu, Chongxuan; Mckinley, James; Serne, R. Jeffrey; and Gassman, Paul, "Sorption of Cs+ to micaceous subsurface sediments from the Hanford site, USA" (2002). US Department of Energy Publications. 251.

https://digitalcommons.unl.edu/usdoepub/251

This Article is brought to you for free and open access by the U.S. Department of Energy at DigitalCommons@University of Nebraska - Lincoln. It has been accepted for inclusion in US Department of Energy Publications by an authorized administrator of DigitalCommons@University of Nebraska - Lincoln. 


\section{Authors}

John M. Zachara, Steven Smith, Chongxuan Liu, James Mckinley, R. Jeffrey Serne, and Paul Gassman 
PII S0016-7037(01)00759-1

\title{
Sorption of $\mathrm{Cs}^{+}$to micaceous subsurface sediments from the Hanford site, USA
}

\author{
John M. Zachara,* Steven C. Smith, Chongxuan Liu, James P. McKinley, R. Jeffrey Serne, and Paul L. Gassman \\ Pacific Northwest National Laboratory, MSIN K8-96, P.O. Box 999, Richland, WA 99352, USA
}

(Received September 28, 2000; accepted in revised form June 27, 2001)

\begin{abstract}
The sorption of $\mathrm{Cs}^{+}$was investigated over a large concentration range $\left(10^{-9}-10^{-2} \mathrm{~mol} / \mathrm{L}\right)$ on subsurface sediments from a United States nuclear materials site (Hanford) where high-level nuclear wastes (HLW) have been accidentally released to the vadose zone. The sediment sorbs large amounts of radiocesium, but expedited migration has been observed when $\mathrm{HLW}$ (a $\mathrm{NaNO}_{3}$ brine) is the carrier. $\mathrm{Cs}^{+}$sorption was measured on homoionic sediments $\left(\mathrm{Na}^{+}, \mathrm{K}^{+}, \mathrm{Ca}^{2+}\right)$ with electrolyte concentrations ranging from 0.01 to 1.0 mol/L. In $\mathrm{Na}^{+}$electrolyte, concentrations were extended to near saturation with $\mathrm{NaNO}_{3(\mathrm{~s})}(7.0 \mathrm{~mol} / \mathrm{L})$. The sediment contained nonexpansible (biotite, muscovite) and expansible (vermiculite, smectite) phyllosilicates. The sorption data were interpreted according to the frayed edge-planar site conceptual model. A fourparameter, two-site (high- and low-affinity) numeric ion exchange model was effective in describing the sorption data. The high-affinity sites were ascribed to wedge zones on the micas where particle edges have partially expanded due to the removal of interlayer cations during weathering, and the low-affinity ones to planar sites on the expansible clays. The electrolyte cations competed with $\mathrm{Cs}^{+}$for both high- and low-affinity sites according to the trend $\mathrm{K}^{+}>>\mathrm{Na}^{+} \geq \mathrm{Ca}^{2+}$. At high salt concentration, $\mathrm{Cs}^{+}$adsorption occurred only on high-affinity sites. $\mathrm{Na}^{+}$was an effective competitor for the high-affinity sites at high salt concentrations. In select experiments, silver-thiourea (AgTU) was used as a blocking agent to further isolate and characterize the high-affinity sites, but the method was found to be problematic. Mica particles were handpicked from the sediment, contacted with $\mathrm{Cs}^{+}{ }_{(\mathrm{aq})}$, and analyzed by electron microprobe to identify phases and features important to $\mathrm{Cs}^{+}$sorption. The microprobe study implied that biotite was the primary contributor of high-affinity sites because of its weathered periphery. The poly-phase sediment exhibited close similarity in ion selectivity to illite, which has been well studied, although its proportion of high-affinity sites relative to the cation exchange capacity (CEC) was lower than that of illite. Important insights are provided on how $\mathrm{Na}^{+}$ in $\mathrm{HLW}$ and indigenous $\mathrm{K}^{+}$displaced from the sediments may act to expedite the migration of strongly sorbing $\mathrm{Cs}^{+}$in subsurface environments. Copyright $(\mathrm{C}) 2002$ Elsevier Science Ltd
\end{abstract}

\section{INTRODUCTION}

${ }^{137} \mathrm{Cs}$ is a high-yield fission product from the irradiation of uranium-based fuels. With a $\mathrm{t}^{1 / 2}$ of $35.7 \mathrm{yr},{ }^{137} \mathrm{Cs}$ is of health concern because of its hard gamma emission. As a contaminant it has been dispersed worldwide in low concentration following atmospheric nuclear arms testing and the Chernoybl accident. ${ }^{137} \mathrm{Cs}$ is a major radioactive component of high-level nuclear wastes (HLW) held in storage by the United States, Canada, and its European allies, and by members of the former Soviet Union. Large concentrations of ${ }^{137} \mathrm{Cs}$ have been released to the environment in a few locations worldwide as a result of nuclear materials accidents. Examples include the Chernoybl accident in the Ukraine, and nuclear processing sites in the U.S. and the former Soviet Union where HLW have been released or disposed to the soil surface, the vadose zone, and groundwater. Concern exists at these locations whether the decay rate of ${ }^{137} \mathrm{Cs}$ will outpace its migration velocity and delivery to receiving waters or biologic receptors.

$\mathrm{Cs}^{+}$is strongly and selectively sorbed by the phyllosilicate fraction of soils, sediments, and suspended particulates (Tamura and Jacobs, 1960; Sawhney, 1970, 1972; Francis and Brinkley, 1976). $\mathrm{Cs}^{+}$engages in ion-exchange reactions with hydrated cations on planar sites on expansible layer silicates (e.g., smectites)

* Author to whom correspondence should be addressed (john.zachara@ pnl.gov). with selectivity trend approximated by the lyotropic series. $\mathrm{Cs}^{+}$ sorbs in highly selective fashion to wedge or frayed edge sites (FES) that develop along the weathered periphery of micas (e.g., biotite and muscovite) and their immediate weathering products (hydrous-mica, illite). The wedge zones form where the 1.0-nm mica core sheet opens to $1.4 \mathrm{~nm}$ vermiculite, where a unique, stereoselective environment is provided for $\mathrm{Cs}^{+}$sorption (Jackson, 1963; Rich and Black, 1964). X-ray absorption spectroscopy measurements imply that strongly sorbed $\mathrm{Cs}^{+}$exists as an innersphere, dehydrated surface complex (Kemner et al., 1997).

The sorption behavior of $\mathrm{Cs}^{+}$in a geologic material is a sensitive consequence of the relative concentrations of smectite/vermiculite and mica/illite as the former are the primary contributors of planar sites, and the latter of wedge or FES sites. In spite of the dependence of $\mathrm{Cs}^{+}$sorption on phyllosilicate type, $\mathrm{Cs}^{+}$sorption correlates strongly with the cation exchange capacity (CEC) as the primary master variable for sorption (Grütter et al., 1990). Methods have been proposed to quantify the concentration and exchange thermodynamics of the FES, relative to the total CEC, using both chemical agents (silver-thiourea, AgTU) to block planar sites (Cremers et al., 1988; De Preter et al., 1991) and adjustment of FES K ${ }^{+}$ saturation (Wauters et al., 1996a,b,c). The FES are highly selective to $\mathrm{Cs}^{+}$and $\mathrm{K}^{+}$. They exhibit heterogeneity in exchange thermodynamics and consequently, selectivity (De Preter et al., 1991), indicating contributions of various microstructural environments such as faults, cleavages, cracks, and stepped edges. 
Nuclear magnetic resonance (NMR) studies of $\mathrm{Cs}^{+}$exchanged layer silicates (Weiss et al., 1990a,b; Kim et al., 1996) have documented the presence of multiple sorption environments generally consistent with the planar site-FES site conceptual model described above. Thermodynamic modeling of $\mathrm{Cs}^{+}$adsorption to layer silicates, illite primarily, has required inclusion of multiple surface sites with dramatically different concentrations and free energies of $\mathrm{Cs}^{+}$complexation. Brouwer et al. (1983) suggested that $\mathrm{Cs}^{+}$exchange to planar and FES sites exhibited reversible thermodynamic behavior over 24-h equilibration times, and devised a three-site thermodynamic model that well described $\mathrm{Cs}^{+}$adsorptive exchange on illite over a large $\mathrm{Cs}^{+}$concentration range with different saturating cations $\left(\mathrm{Rb}^{+}, \mathrm{K}^{+}, \mathrm{Na}^{+}, \mathrm{Ca}^{2+}\right)$. Poinssot et al. (1999) applied a similar model with two sites to describe $\mathrm{Cs}^{+}$adsorption from $\mathrm{Na}^{+}$electrolytes of variable $\mathrm{pH}$ on illite. Key to the latter analysis was the explicit consideration of $\mathrm{K}^{+}$released by dissolution of the sorbent.

As a sorbate, $\mathrm{Cs}^{+}$is somewhat unique in its frequent demonstration of slowly reversible sorption (Comans et al., 1991). This phenomenon apparently results from $\mathrm{Cs}^{+}$dehydration and diffusion within collapsed interlayers of illite or hydromica (Sawhney, 1972; Comans and Hockley, 1992). Accessibility to and exchange reversibility of the FES in illite is dependent on the saturating cation (e.g., $\mathrm{K}^{+}$vs. $\mathrm{Ca}^{2+}$; Comans et al., 1991). Saturation with $\mathrm{Ca}^{2+}$ enabled greater access of $\mathrm{Cs}^{+}$to the FES, and less thermodynamic reversibility. This sorption behavior was described with a kinetic model (Comans and Hockley, 1992) containing an instantaneous/reversible reaction and a longer-term irreversible reaction, operative over days to months.

Here we assess the sorption behavior of $\mathrm{Cs}^{+}$on a subsurface sediment from a nuclear materials site in the United States (Hanford, Washington). This micaceous sediment shows high affinity for $\mathrm{Cs}^{+}$, but cases of expedited $\mathrm{Cs}^{+}$migration have been observed when HLW is the carrier (Serne et al., 1998). Sorption experiments were performed in homoionic sediment/ electrolyte suspensions $\left(\mathrm{Na}^{+}, \mathrm{K}^{+}, \mathrm{Ca}^{+}\right)$, and in $\mathrm{Na}^{+}$electrolyte (the primary cation in HLW) were extended to near saturation with $\mathrm{NaNO}_{3(\mathrm{~s})}$ (many of the HLW at Hanford contain sodium nitrate salt-cake). AgTU was used as a blocking agent for planar sites in select experiments. A large $\mathrm{Cs}^{+}$concentration range $\left(10^{-9}-10^{-2} \mathrm{~mol} / \mathrm{L}\right)$ was used to allow saturation of both FES and planar sites. Weathered micas of different types were picked from the sediments, contacted with $\mathrm{CsNO}_{3(\mathrm{aq})}$, and analyzed by electron microprobe to identify $\mathrm{Cs}^{+}$-selective phases and features. A multisite model was used to interpret the sorption data and to provide insights on the AgTU/FES site characterization method. This sediment, which fortuitously resides beneath HLW tanks at Hanford that have leaked over 1 million $\mathrm{Ci}$ of ${ }^{137} \mathrm{Cs}$, serves as an excellent material to illustrate the complex interdependent effects of mineralogy, site distribution/energetics, and electrolyte on $\mathrm{Cs}^{+}$adsorption.

\section{EXPERIMENTAL PROCEDURES}

\subsection{Collection, Preparation, and Processing of Sediment}

Core samples from the placement of four Resource Conservation and Recovery Act (RCRA) monitoring wells surrounding the S-SX tank farm ranging in depth from 9 to $21.3 \mathrm{~m}$ below surface were composited and mixed to homogeneity. The samples were all derived from the Hanford formation, flood deposits of Pleistocene age. The material was lightly crushed to pass a 2-mm sieve, air-dried, and mixed thoroughly. A subsample of the composite sediment ("Above B") was sieved into size fractions of 1000 to $2000 \mu \mathrm{m}, 500 \mu \mathrm{m}$ to $1000 \mu \mathrm{m}, 250$ to 500 $\mu \mathrm{m}, 125$ to $250 \mu \mathrm{m}, 63$ to $125 \mu \mathrm{m}$, and $<63 \mu \mathrm{m}$.

\subsection{Mineralogical Determination}

A bulk sample of the "Above B" sediment was dry-sieved to obtain particle size separates of sands and silts for mineralogical analyses. Dry sieving was performed to decrease the likelihood of removing soluble mineral phases during separations.

Micas were concentrated for mineralogical analysis and sorption study by hand picking from the $0.5-2.0 \mathrm{~mm}$ size isolate. These were analyzed by X-ray diffraction (XRD) and optical microscopy. Large mica crystals enabled segregation into subsamples of muscovite, biotite, and a weathered intermediate presumed to be vermiculitized biotite. The biotite and vermiculitized biotite exhibited a drusy, creamcolored phase on basal surfaces.

Clay $(<2 \mu \mathrm{m})$ was isolated from the bulk sediment by suspending the sediment in a dilute electrolyte, and isolating the clays by centrifugation. The sediment did not receive pretreatment to remove free iron or organic matter, being largely free of the aggregating effects of these soil components. Subsamples of the clay isolate received saturations with $\mathrm{KCl}$ and $\mathrm{MgCl}_{2}$ and were washed free of excess salt. The Mgsaturated sample was then glycol solvated.

XRD analyses were conducted using a GE-Diano 8535 X-ray diffractometer equipped with a graphite monochromometer and using $\mathrm{Cu}-\mathrm{K} \alpha$ radiation. Data were collected by step-scan from 2 to $70^{\circ} 2 \theta$. Discrete particle size separates of silts $(<63 \mu \mathrm{m})$ and sands $(63-125$ $\mu \mathrm{m}, 125-250 \mu \mathrm{m}$, and $250-500 \mu \mathrm{m}$ ) were analyzed as powder mounts. The powders were loaded into a well mount without attempting particle orientation. The muscovite, biotite, and vermiculitized biotite samples were oriented on double-sided tape for XRD analysis. Clay isolates were also analyzed by XRD as preferentially oriented samples.

\subsection{Extraction of Carbonates}

One $\mathrm{kg}$ of the "Above B" composite was treated with $1 \mathrm{~mol} / \mathrm{L}$ sodium acetate $(\mathrm{NaOAc}) \mathrm{pH} 5.0$ (with acetic acid) to dissolve carbonates $\left(\mathrm{NaHCO}_{3}\right.$ and $\left.\mathrm{CaCO}_{3}\right)$ and soluble salts. Approximately $200 \mathrm{~g}$ of sediment were loaded into $60 \mathrm{~cm}$ of SpectraPor \#7 cellulose dialysis tubing and combined with $200 \mathrm{~mL}$ of $\mathrm{NaOAc}$ solution. Dialysis tubes containing the sediment were placed in $3 \mathrm{~L}$ of $\mathrm{NaOAc}$ solution for 3 days. Occasional mixing of the suspension in the tubing allowed complete extraction of the sediment. After three days of extraction, the dialysate was discarded and replaced with $3 \mathrm{~L}$ of fresh $1 \mathrm{~mol} / \mathrm{L} \mathrm{NaOAc}$. After two additional days the dialysate was discarded and replaced with deionized water. The dialysate was frequently replaced over $2 \mathrm{~d}$, and then replaced with $1 \mathrm{mmol} / \mathrm{L} \mathrm{NaHCO}_{3}$ to neutralize the suspension $\mathrm{pH}$. The $1 \mathrm{mmol} / \mathrm{L} \mathrm{NaHCO}_{3}$ was replaced daily for $3 \mathrm{~d}$, and then replaced with deionized water. The sediment was dialyzed against deionized water until the electrical conductivity of the dialysate remained below $5 \mu \mathrm{S} / \mathrm{cm}$ after overnight equilibration. The extracted and washed sediment was air-dried and thoroughly mixed.

\subsection{CEC Determinations}

The CEC of NaOAc-treated sediment was determined using $\mathrm{Na}^{+}$, $\mathrm{Ca}^{2+}$, or $\mathrm{K}^{+}$saturated material. Isotopic exchange with either ${ }^{22} \mathrm{Na}$ or ${ }^{45} \mathrm{Ca}$ in $0.002 \mathrm{~mol} / \mathrm{L} \mathrm{NaNO}_{3}$ or $0.001 \mathrm{~mol} / \mathrm{L} \mathrm{Ca}\left(\mathrm{NO}_{3}\right)_{2}$ electrolytes, respectively, was used to determine the surface excess of these cations (Babcock and Schulz, 1970). The aqueous-phase activity of ${ }^{22} \mathrm{Na}$ and ${ }^{45} \mathrm{Ca}$ after $16 \mathrm{~h}$ equilibration was determined by liquid scintillation counting, and $\mathrm{Na}^{+}{ }_{\text {aq }}$ and $\mathrm{Ca}^{2+}{ }_{\text {aq }}$ by inductively coupled argon plasma emission spectroscopy (ICP-AES). The following relationship (shown only for $\left.{ }^{22} \mathrm{Na}\right)$ was used to compute the CEC: $\left({ }^{22} \mathrm{Na} / \mathrm{Na}^{+}\right)$aq $=\left({ }^{22} \mathrm{Na} /\right.$ $\left.\mathrm{Na}^{+}\right)_{\text {soil }}$. The ${ }^{22} \mathrm{Na}$ in the soil was calculated as the difference between the known amount added and the final aqueous concentration.

The $\mathrm{K}^{+}$exchange capacity of the sediment was measured by extracting with $0.1 \mathrm{~mol} / \mathrm{L}$ ammonium acetate. The $\mathrm{K}^{+}$concentration in the extract was measured by ICP-AES. 


\subsection{Preparation of Cesium Solutions}

Cesium nitrate (Johnson Matthey, lot \# 015016, f.w. = 194.91) solutions were used to spike suspensions with the sorbent of interest. Radiolabeled ${ }^{137} \mathrm{Cs}$ (as $\mathrm{CsCl}$ in $0.1 \mathrm{~mol} / \mathrm{L} \mathrm{HCl}$ ) was added as desired. Its activity was $3.7 \times 10^{6} \mathrm{mCi} / \mathrm{mol}$.

\subsection{Preparation of Silver Thiourea Solution}

Dissolved silver nitrate (Fisher, lot \# 977802, f.w. $=169.87$ ) was added to dissolved thiourea (Fisher, lot \# 962014, f.w. $=76.12$ ) to prepare $0.015 \mathrm{~mol} / \mathrm{L} \mathrm{AgTU}$. The molar ratio of the final solution was 3:1, thiourea:silver nitrate. Care was taken to ensure that the freshly prepared AgTU solution was used within $48 \mathrm{~h}$ after preparation and that its $\mathrm{pH}$ did not exceed a value of 8 . Exposure to light was minimized to prevent light-induced reduction of thiourea and the formation of $\mathrm{Ag}_{2} \mathrm{~S}$.

\subsection{Cesium Sorption on Untreated Hanford "Above B" Sediment}

Cesium sorption isotherms on the $<63 \mu \mathrm{m}$ and 125 to $250 \mu \mathrm{m}$ size fractions of untreated "Above B" sediment were measured in 7 (near saturated), 5, and $0.005 \mathrm{~mol} / \mathrm{L} \mathrm{NaNO}_{3}$. The solid material was washed two times in the appropriate electrolyte before addition of $\mathrm{CsNO}_{3}$. The solids concentrations in these and the experiments below (Section 2.8) were adjusted so that the percentage adsorption of Cs would range, for the most part, between $15 \%$ and $85 \%$. While some measurements fell outside of this range (e.g., for the extremes in electrolyte and Cs concentration), experimental error was minimized within it. Solids concentrations were $100 \mathrm{~g} / \mathrm{L}$ and $250 \mathrm{~g} / \mathrm{L}$ for the $<63 \mu \mathrm{m}$ or 125 to 250 $\mu \mathrm{m}$ fractions in 7 or $5 \mathrm{~mol} / \mathrm{L}$ electrolytes, and 5 or $10 \mathrm{~g} / \mathrm{L}$ in the 0.005 $\mathrm{mol} / \mathrm{L}$ electrolyte, respectively. The $\mathrm{CsNO}_{3}$ concentrations ranged from $10^{-7}$ to $10^{-2} \mathrm{~mol} / \mathrm{L}$ and were labeled with $7000 \mathrm{dpm} / \mathrm{mL}{ }^{137} \mathrm{Cs}$. The suspensions were shaken in $50-\mathrm{mL}$ polycarbonate tubes at $80 \mathrm{rpm}$ and $30^{\circ} \mathrm{C}$ for $16 \mathrm{~h}$. Solid-liquid phase separation was accomplished by centrifuging the tubes at $5000 \mathrm{rcf}$ for $30 \mathrm{~min}$. The ${ }^{137} \mathrm{Cs}$ in the aqueous phase was determined by gamma counting. In this and all other experiments containing ${ }^{137} \mathrm{Cs}$, over 10,000 counts were obtained for radioanalyte quantification yielding a counting error of $<1 \%$. The suspension $\mathrm{pH}$ was measured using a glass combination electrode calibrated using $\mathrm{pH} 7.00$ and 4.01 buffers.

\subsection{Cesium Sorption Isotherms on NaOAc-treated "Above B" Sediment}

Cesium sorption isotherms on NaOAc-treated "Above B" sediment were measured in $\mathrm{NaNO}_{3}, \mathrm{KNO}_{3}$, and $\mathrm{Ca}\left(\mathrm{NO}_{3}\right)_{2}$ electrolytes of various concentrations. Solids used in the $\mathrm{Ca}^{2+}$ and $\mathrm{K}^{+}$electrolytes were washed three times in the appropriate electrolyte and resuspended before addition of $\mathrm{CsNO}_{3}$. The solids concentrations in Na electrolyte were $100 \mathrm{~g} / \mathrm{L}, 50 \mathrm{~g} / \mathrm{L}, 10 \mathrm{~g} / \mathrm{L}$, and $2 \mathrm{~g} / \mathrm{L}$ in $5,1,0.1$, and $0.01 \mathrm{~mol} / \mathrm{L}$ $\mathrm{NaNO}_{3}$, respectively. The solids concentrations in Ca electrolyte were $50 \mathrm{~g} / \mathrm{L}$ (and $5 \mathrm{~g} / \mathrm{L}$ ), $10 \mathrm{~g} / \mathrm{L}$ (and $2 \mathrm{~g} / \mathrm{L}$ ), and $2 \mathrm{~g} / \mathrm{L}$ in $0.5,0.05$, or 0.005 $\mathrm{mol} / \mathrm{L} \mathrm{Ca}\left(\mathrm{NO}_{3}\right)_{2}$, respectively. The solids concentrations in $\mathrm{K}$ electrolyte were $50 \mathrm{~g} / \mathrm{L}, 10 \mathrm{~g} / \mathrm{L}$, and $2 \mathrm{~g} / \mathrm{L}$ in $1,0.1$, and $0.01 \mathrm{~mol} / \mathrm{L} \mathrm{KNO}_{3}$, respectively. Cesium nitrate concentrations ranged from $10^{-9}$ to $10^{-1}$, $\mathrm{mol} / \mathrm{L}$, and were labeled with $7 \times 10^{-3}$ to $2.00 \times 10^{-4} \mathrm{dpm} / \mathrm{mL}{ }^{137} \mathrm{Cs}$. The suspensions were shaken in 50-mL polycarbonate tubes or Nalgene high-density polyethylene bottles at $80 \mathrm{rpm}$ and $30^{\circ} \mathrm{C}$ for $16 \mathrm{~h}$. Phase separation, gamma-counting, and $\mathrm{pH}$ measurements were accomplished as described above.

\subsection{Cesium Desorption Kinetic Study}

Sodium-acetate extracted Hanford "Above B" sediment $(<2 \mathrm{~mm}$ size fraction) was contacted with $10^{-4} \mathrm{~mol} / \mathrm{L} \mathrm{Cs}^{+}\left(\right.$as $\left.\mathrm{CsNO}_{3}\right)$ in either $5\left(6.66 \times 10^{-6} \mathrm{dpm} / \mathrm{mL}^{137} \mathrm{Cs}\right)$ or $0.005\left(6.66 \times 10^{5} \mathrm{dpm} / \mathrm{mL}^{137} \mathrm{Cs}\right)$ $\mathrm{mol} / \mathrm{L} \mathrm{NaNO}_{3}$ electrolyte using polypropylene Falcon centrifuge tubes. The solid concentrations during the adsorption phase of the experiment were: $100 \mathrm{~g} / \mathrm{L}(0.50 \mathrm{~g} / 5 \mathrm{~mL})$ in the $5 \mathrm{~mol} / \mathrm{L} \mathrm{Na}$ electrolyte and $5 \mathrm{~g} / \mathrm{L}$ $(0.25 \mathrm{~g} / 50 \mathrm{~mL})$ in the $0.005 \mathrm{~mol} / \mathrm{L}$ Na electrolyte. The contact times for the adsorption period were, $0.5,1,4,10,20,3060$, and $120 \mathrm{~d}$. The suspensions were equilibrated at room temperature on a bench-top shaker at $100 \mathrm{rpm}$. After the adsorption period, the tubes were centrifuged as described previously and the supernatant removed. Forty-five $\mathrm{mL}$ of $0.1 \mathrm{~mol} / \mathrm{L} \mathrm{KNO}_{3}$ was then added to each tube to initiate the $\mathrm{Cs}^{+}$ desorption. The $\mathrm{K}^{+}$-spiked suspensions were then shaken as described previously. The extent of desorption was periodically determined $(2 \mathrm{~h}$, 5 or $6 \mathrm{~h}, 24 \mathrm{~h}, 2 \mathrm{~d}, 4$ or $5 \mathrm{~d}, 9$ or 10 or $11 \mathrm{~d}$, and 20 or $21 \mathrm{~d}$ ) by centrifuging the suspension and removing $2-\mathrm{mL}$ replicate samples of the supernatant. The extent of desorption was determined by counting ${ }^{137} \mathrm{Cs}$ in the supernatant.

\subsection{Cesium Sorption Isotherms on NaOAc-treated "Above B" Sediment in Electrolyte Containing AgTU}

A cesium sorption isotherm on NaOAc-treated "Above B" sediment was performed in $0.015 \mathrm{~mol} / \mathrm{L} \mathrm{AgTU}^{+}-\mathrm{NO}_{3}^{-}$. The solids were not washed before addition of $\mathrm{CsNO}_{3}$. Suspensions contained $2 \mathrm{~g} / \mathrm{L}$ solid and $\mathrm{CsNO}_{3}$ from $10^{-2}$ to $10^{-9} \mathrm{~mol} / \mathrm{L}$ with $15,000 \mathrm{dpm} / \mathrm{mL}^{137} \mathrm{Cs}$. The suspensions were shaken in either 120 or $250 \mathrm{~mL}$ Nalgene high-density polyethylene bottles at $80 \mathrm{rpm}$ and $30^{\circ} \mathrm{C}$ for $16 \mathrm{~h}$. Phase separation, gamma-counting, and $\mathrm{pH}$ measurements were accomplished as described above.

Cesium sorption selectivity on NaOAc-treated "Above B" sediment in electrolyte containing $0.015 \mathrm{~mol} / \mathrm{L} \mathrm{AgTU}{ }^{+}-\mathrm{NO}_{3}^{-}, 0.1 \mathrm{~mol} / \mathrm{L} \mathrm{KNO}$, and various cesium concentrations was also determined. The solid concentrations used were $40 \mathrm{~g} / \mathrm{L}\left(10^{-3.0}\right.$ to $\left.10^{-5.0} \mathrm{~mol} / \mathrm{L} \mathrm{CsNO}_{3}\right), 20$ $\mathrm{g} / \mathrm{L}\left(10^{-5.5}\right.$ to $\left.10^{-7.5} \mathrm{~mol} / \mathrm{L} \mathrm{CsNO}_{3}\right)$, and $10 \mathrm{~g} / \mathrm{L}\left(10^{-8.0}\right.$ to $10^{-9.0}$ $\mathrm{mol} / \mathrm{L} \mathrm{CsNO}_{3}$ ). The solids were washed three times in the desired electrolyte before being spiked with $\mathrm{CsNO}_{3}$ containing $17,000 \mathrm{dpm} / \mathrm{mL}$ ${ }^{137} \mathrm{Cs}$. The suspensions were shaken in $50-\mathrm{mL}$ polycarbonate tubes at $80 \mathrm{rpm}$ and $30^{\circ} \mathrm{C}$ for $16 \mathrm{~h}$. Phase separation, gamma-counting, and $\mathrm{pH}$ measurements were accomplished as described above.

\subsection{Electron Microprobe Analyses of Cs-spiked Micas}

Micas were picked from the sediment under a binocular microscope and segregated according to appearance. Three micas were identified: colorless muscovite (most abundant), rust colored vermiculite (least abundant), and black biotite. Mica flakes were suspended in solutions of $0.01 \mathrm{M} \mathrm{CsNO}_{3}$ for $28 \mathrm{~d}$, then rinsed and air-dried. Individual flakes were fixed to glass slides and carbon-coated before electron microprobe (EMP) analysis.

A JEOL model 8600 microprobe was used for image acquisition, operating at an accelerating potential of $20 \mathrm{KeV}$ and $20 \mathrm{nA}$ beam current. Individual wavelength-dispersive spectrometers were tuned to characteristic $\mathrm{Cs}^{+}$and $\mathrm{K}^{+}$energies during data collection. Individual mica flakes were imaged by defining uniformly sized areas approximately $120 \mu \mathrm{m}$ square on each flake. Each area was divided into $256 \times$ 256 pixels and scanned for $100 \mathrm{~ms} \mathrm{pixel}^{-1}$, five times, for a total measurement time of $500 \mathrm{~ms}$ pixel $^{-1}$. Digital images of radiation intensity for $\mathrm{K}^{+}$and $\mathrm{Cs}^{+}$were treated differently. For comparison between flakes, the background intensity levels of $\mathrm{Cs}^{+}$images were equalized, and the image brightness and contrast levels were not further manipulated. For $\mathrm{K}^{+}$, brightness and contrast levels were adjusted to provide the (subjectively) best presentation of flake morphology.

\section{RESULTS}

\subsection{Sediment Properties}

Particle size distribution of the sediment (silt and sand) as determined by dry screening (Table 1) categorized the sediment as a sandy silt. Sedimentation analysis showed that the sediment contained $2.7 \%$ clay $(<2.0 \mu \mathrm{m})$. The CEC varied with saturating ion (Table 2) and were relatively low because of the small amount of clay. The higher CEC in $\mathrm{K}^{+}$was consistent with a significant micaceous mineral fraction as described below, but its large excess over that in $\mathrm{Ca}^{2+}$ and $\mathrm{Na}^{+}$electrolyte was not easily explained. The CEC measurements were repeated six times to ensure that these measurements were reproducible. 
Table 1. Dry sieve analysis of the 'Above-B' sediment.

\begin{tabular}{lc}
\hline \multicolumn{1}{c}{ Size } & Mass \% \\
\hline $1.0-2.0 \mathrm{~mm}$ & 1.4 \\
$0.5-1.0 \mathrm{~mm}$ & 4.8 \\
$250-500 \mu \mathrm{m}$ & 17.5 \\
$125-250 \mu \mathrm{m}$ & $36.8^{*}$ \\
$63-125 \mu \mathrm{m}$ & 30.2 \\
$<63 \mu \mathrm{m}$ & $9.3^{*}$ \\
\hline
\end{tabular}

* Used in particle isolate studies.

\subsection{Mineralogy}

The weight percentages of the mineral constituents varied with particle size. Quartz was the dominant mineral in all particle sizes greater than $2 \mu \mathrm{m}$, with lesser amounts of plagioclase and potassium feldspars, micas, chlorite, vermiculite, and smectite (Fig. 1). The feldspar content decreased with decreasing particle size; however, some of this effect may be due to decreasing domain size of the crystallites. Most of the feldspar was plagioclase with anorthite being the dominant phase. Chlorite and smectite were clay minerals whose presence in silt and sand sized separates indicated incomplete disaggregation during sieve separation. Accordingly, their weight percentages increased with decreasing particle size.

Micas were handpicked from the sand fraction to facilitate their analyses. XRD showed the micas $(0.5-2.0 \mathrm{~mm})$ to be muscovite, biotite, and vermiculitized biotite (Fig. 2). Muscovite grains were generally larger than those of biotite and vermiculitized biotite, and were nearly optically clear. Few, if any, inclusions or staining were observed in the muscovite grains. The larger crystallite size of muscovite is consistent with the dioctahedral micas being more resistant to weathering than trioctahedral biotite and vermiculitized biotite.

It was noted during isolation and mounting of the mica samples that a cream-colored encrustation existed on the basal surfaces of biotite and vermiculitized biotite. These encrustations were identified as feldspar by diffraction peaks at 6.6 and $3.18 \AA$. The vermiculite exhibited only a very weak feldspar peak at $6.6 \AA$.

The vermiculitized biotite possessed strong $14.3 \AA$ and $7.18 \AA$ peaks as well as strong basal reflections of biotite. The basal surfaces of the vermiculitized biotite flakes were highly weathered yielding the vermiculite layers, whereas the internal surfaces were unaltered biotite. Conversely, basal surfaces of the biotite grains appeared unaltered yet they exhibited weak dspacings for vermiculite. Surprisingly, even the muscovite exhibited weak diffraction peaks of vermiculite.

Optical microscopy revealed that conversion of biotite to vermiculite created corrugated basal surfaces. In reflected light the vermiculitized basal layers possessed a brassy yellow sheen, which was accentuated by the corrugated surface topology. In transmitted light, the vermiculite was bright red and the biotite dark brown, consistent with oxidation of octahedrally coordinated iron during weathering. The vermiculite exhibited no pleochroism, whereas biotite did.

The clay fraction consisted of smectite, chlorite (clinochlore), and mica (Fig. 3). The Mg-saturated, glycerol-solvated clay preparation displayed an intense but very broad diffraction
Table 2. Cation exchange capacities and $\mathrm{Cs}^{+}$sorption maxima in different electrolytes.

\begin{tabular}{lcc}
\hline Index Ion & $\begin{array}{c}\text { CEC }\left(\mathrm{eq} / \mathrm{g} \times 10^{-5}\right) \\
\mathrm{n}=6\end{array}$ & $\begin{array}{c}\text { Max Cs adsorption } \\
\left(\mathrm{eq} / \mathrm{g} \times 10^{-5}\right)^{\mathrm{a}} \mathrm{n}=4\end{array}$ \\
\hline $\mathrm{Na}^{+}$ & $4.26+/-.12$ & 5.79 \\
$\mathrm{~K}^{+}$ & $8.25+/-.35$ & 3.61 \\
$\mathrm{Ca}^{+}$ & $4.69+/-.14$ & 6.22 \\
\hline
\end{tabular}

${ }^{a}$ Observed in the lowest ionic strength of each electrolyte.

maxima for smectite at approximately $19 \AA$ that did not fully collapse heating to $110^{\circ} \mathrm{C}$. In spite of the identification of vermiculite in association with sand-sized biotite particles (Fig. 2), a distinct basal reflection for vermiculite was not observed in the clay fraction, possibly because it was subsumed within the broad smectite peak. Other ion saturation $\left(\mathrm{K}^{+}\right)$and heating treatments of the clay fraction, however, did not show the unequivocal presence of vermiculite in the fine fraction.

\section{3. $\mathrm{Cs}^{+}$Adsorption Chemistry from $\mathrm{Na}^{+}, \mathrm{K}^{+}$, and $\mathrm{Ca}^{2+}$ Electrolytes}

The adsorption of $\mathrm{Cs}^{+}$was investigated in $\mathrm{Na}^{+}, \mathrm{K}^{+}, \mathrm{Ca}^{2+}$ electrolytes (homoionic sediment), as these are the prominent saturating cations in the vadose zone sediment. Most experiments were performed under homoionic conditions with NaOAc ( $\mathrm{pH} 4.5$ ) extracted sediments to remove carbonates. The $\mathrm{pH}$ of the $\mathrm{Cs}^{+}$sorption experiments with the extracted sediments ranged from 5.5 to 6.9 ; those for the pristine sediment ranged from 7.5 to 9.0. The high $\mathrm{Na}^{+}$electrolytes lead to lower measured $\mathrm{pH}$ values because of the $\mathrm{Na}^{+}$effect on the glass electrode. We did not observe any apparent $\mathrm{pH}$ effects on $\mathrm{Cs}^{+}$ adsorption nor did we expect them (Poinssot et al., 1999). Comparisons were made between the extracted and unextracted sediments. Very similar results were obtained, but the pristine sediments released appreciable $\mathrm{Mg}^{2+}, \mathrm{Sr}^{2+}$, and $\mathrm{Ca}^{2+}$ that complicate interpretation.

The adsorption isotherms of $\mathrm{Cs}^{+}$in $\mathrm{Na}^{+}$and $\mathrm{K}^{+}$electrolytes with the $\mathrm{Na}-\mathrm{OAc}$ extracted sediment were dependent on electrolyte concentration (Fig. 4). The adsorption measurements displayed an average relative standard deviation [(std. dev./ mean) $\times 100 \%$ ] of $3.31 \%$. The individual isotherms displayed greater and lower variance from this average (Table 3). Electrolyte concentration was less important with $\mathrm{Ca}^{2+}$. The isotherms were of the Freundlich type with slopes below unity (Freundlich $1 / \mathrm{n}<1$ ), implying sorption site heterogeneity. $\mathrm{Cs}^{+}$ adsorption from $\mathrm{K}^{+}$electrolyte was the most linear of those studied (e.g., isotherm slope $=0.85-0.95$ ). Increasing salt uniformly displaced the isotherms in both $\mathrm{Na}^{+}$and $\mathrm{K}^{+}$electrolyte, indicating adsorption by ion exchange.

The adsorption data were reformatted in terms of surface $(E)$ and aqueous $(\tilde{E})$ equivalent fractions where

$$
\mathrm{E}_{\mathrm{Cs}}=\mathrm{q}_{\mathrm{Cs}} / \mathrm{Q} \text { and } \tilde{\mathrm{E}}_{\mathrm{Cs}}=\left[\mathrm{Cs}^{+}\right] / \tilde{\mathrm{Q}}
$$

where $\mathrm{q}_{\mathrm{Cs}}$ was the adsorption density in mole/g, $\mathrm{Q}$ was the electrolyte-specific CEC (e.g., Table 2), $\left[\mathrm{Cs}^{+}\right]$was the aqueous concentration in mol/L, and Q was the total solution normality. The $\mathrm{Cs}^{+}$adsorption data for the monovalent exchange systems $\left(\mathrm{Na}^{+}, \mathrm{K}^{+}\right)$reduced to single exchange isotherms over wide 


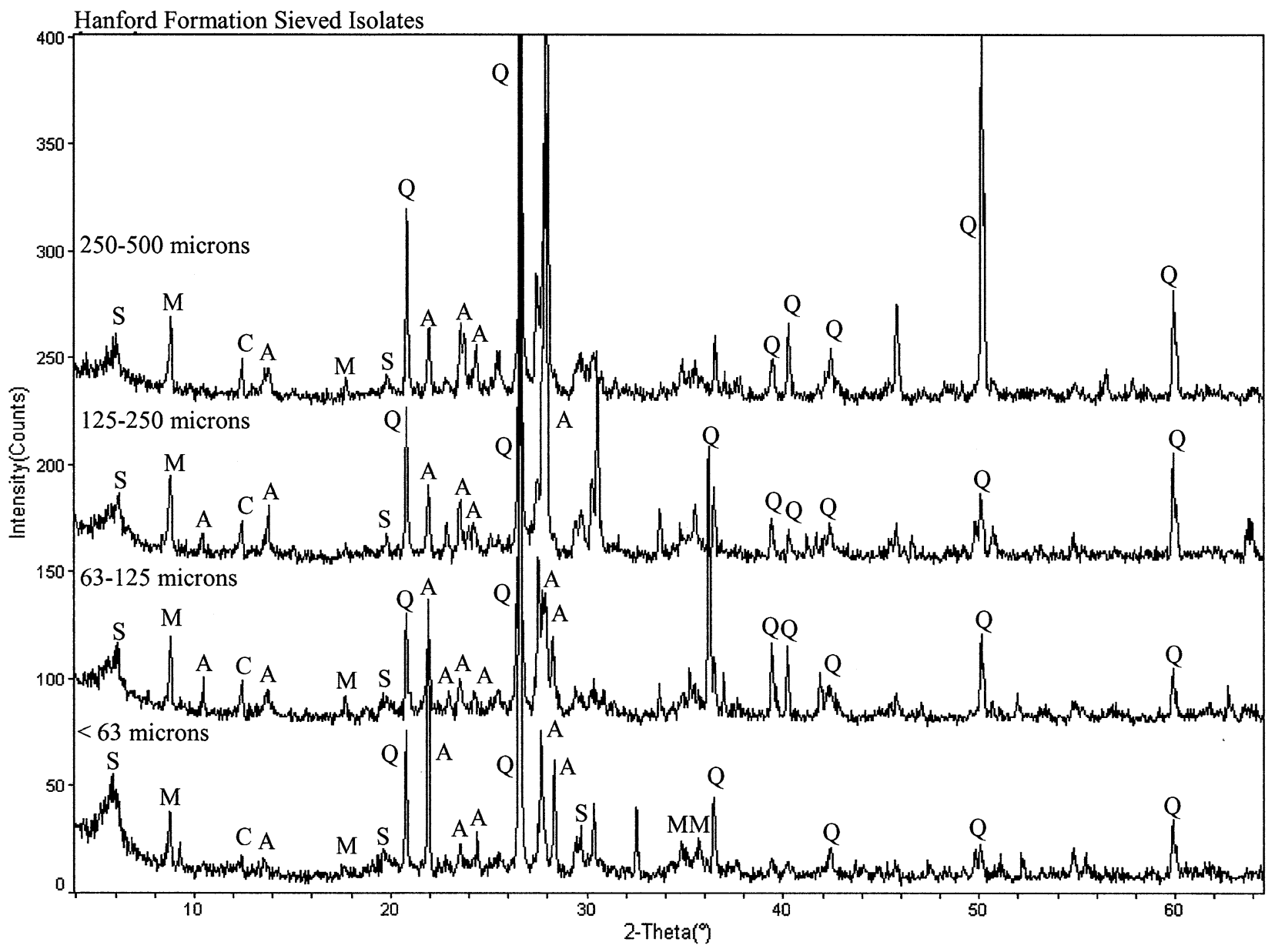

Fig. 1. XRD patterns of random mounts of different particle size isolates of the Hanford sediment. $\mathrm{S}=$ smectite; $\mathrm{M}=$ mica; $\mathrm{C}=$ chlorite; $\mathrm{A}=$ anorthite; $\mathrm{Q}=$ quartz.

ranges in surface and aqueous equivalent fractions $\left(\log \mathrm{E}_{\mathrm{CsX}}\right.$ versus $\log \tilde{\mathrm{E}}_{\mathrm{Cs}(\mathrm{aq})}$ ), while three parallel but distinct ion exchange isotherms resulted for $\mathrm{Ca}^{2+}$ electrolyte (Fig. 4).

The distribution ratio, $\mathrm{K}_{\mathrm{d}}\left[\mathrm{K}_{\mathrm{d}}(\mathrm{L} / \mathrm{g})=\left(\mathrm{mol} \mathrm{Cs}{ }^{+} / \mathrm{g}\right) /(\mathrm{mol}\right.$ $\left.\left.\mathrm{Cs}^{+} / \mathrm{L}\right)\right]$, is a paramater used to describe sorption strength in radionuclide performance assessment models. Here, $\mathrm{K}_{\mathrm{d}}$ decreased with increasing salt concentration and surface loading (Fig. 4). The effect of increasing $\mathrm{Na}^{+}$and $\mathrm{K}^{+}$were generally comparable. The effect of salt concentration was so dramatic that large differences in sorbent concentrations were required to obtain statistically significant sorption measurements. The decrease in $\mathrm{K}_{\mathrm{d}}$ with adsorption density was smallest in $\mathrm{K}^{+}$ electrolyte, but was as much as three orders of magnitude in $\mathrm{Ca}^{2+}$ electrolyte. At high salt $\left(\mathrm{Na}^{+}\right.$and $\left.\mathrm{K}^{+}\right)$and higher $\mathrm{Cs}^{+}$ concentrations, adsorption was negligible [e.g., $\mathrm{K}_{\mathrm{d}}(\mathrm{ml} / \mathrm{g})=0$, or $\left.\log \mathrm{K}_{\mathrm{d}}(\mathrm{L} / \mathrm{g})<-3\right]$. The competitive effect of the electrolyte ions on $\mathrm{Cs}^{+}$sorption followed the trend $\mathrm{K}^{+}>>\mathrm{Na}^{+} \geq \mathrm{Ca}^{2+}$.

\subsection{Ion Exchange Behavior}

Conditional equilibrium constants $\left(\mathrm{K}_{\mathrm{c}}\right)$ were computed from the data in Figure 4 according to the following relationships (Fig. 5).

$$
\begin{aligned}
& \mathrm{uCs}_{(\mathrm{aq})}^{+}+\mathrm{AX}_{\mathrm{u}}=\mathrm{uCsX}+\mathrm{A}_{(\mathrm{aq})}^{\mathrm{u}^{+}} \\
& \mathrm{K}_{\mathrm{c}}=\left[\mathrm{A}^{\mathrm{u}+}\right]\left[\mathrm{E}_{\mathrm{CsX}}\right]^{\mathrm{u}} /\left[\mathrm{Cs}^{+}\right]^{\mathrm{u}}\left[\mathrm{E}_{\mathrm{AXu}}\right]
\end{aligned}
$$

where $\mathrm{A}^{\mathrm{u}+}=\mathrm{Na}^{+}, \mathrm{K}^{+}$, or $\mathrm{Ca}^{2+}$ and [] is concentration. $\mathrm{E}_{\mathrm{CsX}}$ was defined as in Eq. (1) and $\mathrm{E}_{\mathrm{AXu}}$ as $1-\mathrm{E}_{\mathrm{CsX}}$. Because the maximum observed $\mathrm{Cs}^{+}$sorption capacity exceeded the CEC in $\mathrm{Na}^{+}$and $\mathrm{Ca}^{2+}$ electrolyte (Table 2), the highest $\mathrm{Cs}^{+}$concentration was not used in the $\mathrm{K}_{\mathrm{c}}$ computation. The resulting $\mathrm{K}_{\mathrm{c}}$ values were equivalent to the Vanselow model for homoionic, monovalent (e.g., $\mathrm{Na}^{+}-\mathrm{Cs}^{+}, \mathrm{K}^{+}-\mathrm{Cs}^{+}$) exchange, and to the Gaines and Thomas model for heterovalent (e.g., $\mathrm{Ca}^{2+}-\mathrm{Cs}^{+}$) exchange (Sposito, 1981a).

The $\mathrm{K}_{\mathrm{c}}$ values showed strong compositional dependence. In monovalent electrolyte, $\mathrm{K}_{\mathrm{c}}$ increased abruptly below $\mathrm{E}_{\mathrm{CsX}}=$ 0.01 , whereas $\mathrm{K}_{\mathrm{c}}$ in $\mathrm{Ca}^{2+}$ electrolyte showed a monotonic increase with decreasing mole fraction of $\mathrm{Cs}^{+}$. All experiments showed a leveling or approximately constant $\mathrm{K}_{\mathrm{c}}$ below a $\log$ $\mathrm{E}_{\mathrm{CsX}}=-4.5$. The magnitude of these $\mathrm{K}_{\mathrm{c}}$ values in the three electrolytes and their trend with respect to adsorption density were similar to those reported for the Morris and Fithian illites by Brouwer et al. (1983) and Comans et al. (1991). A clear trend in $\mathrm{K}_{\mathrm{c}}$ with respect to electrolyte concentration was not 


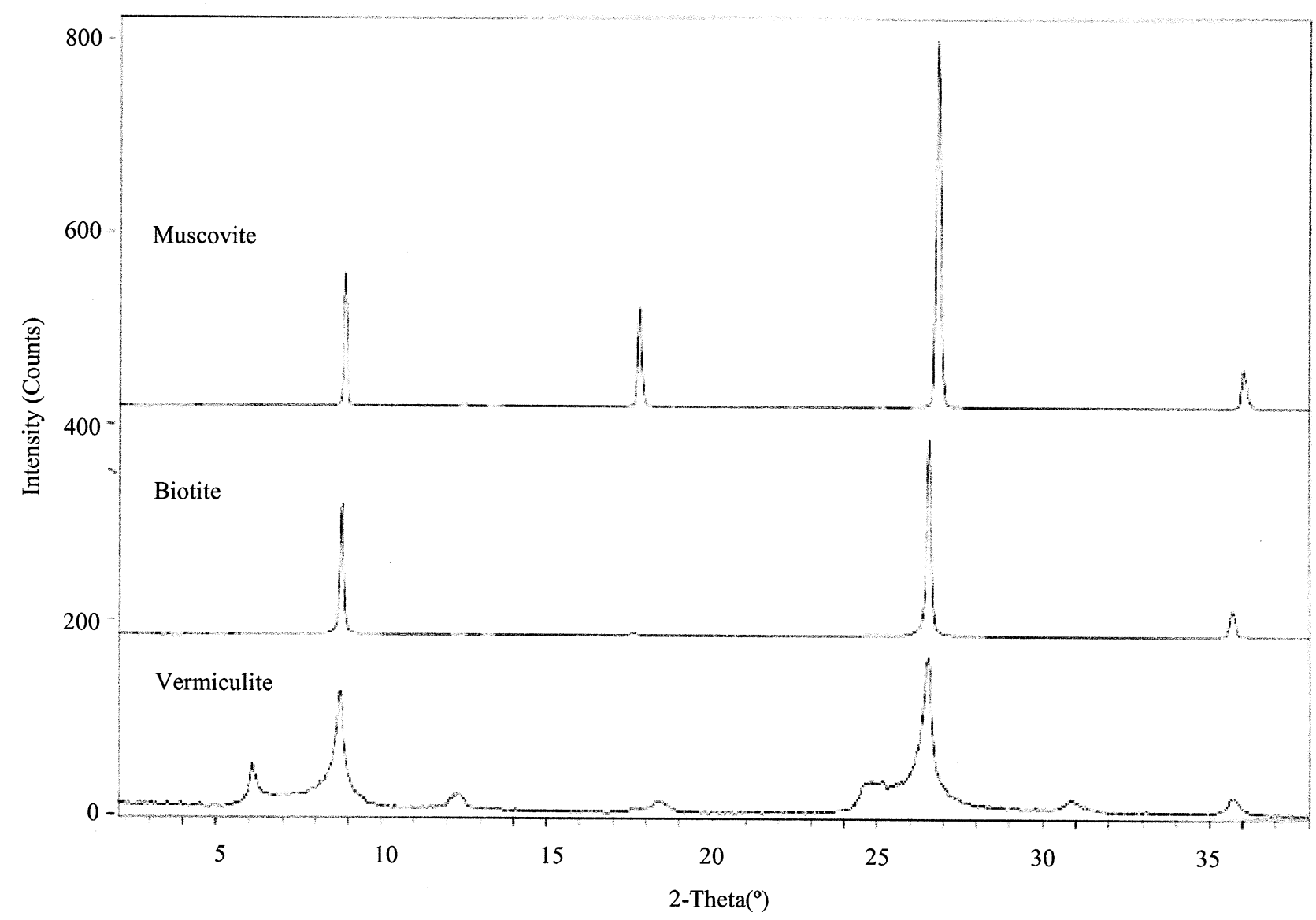

Fig. 2. XRD patterns of the three types of micas present in the Hanford sediment that were picked from the 0.5-2.0-mm size class. The samples were analyzed as oriented mounts of coarse grains on double-sided tape.

observed, but there was a tendency for $\mathrm{K}_{\mathrm{c}}$ to be higher at high I.

A multisite ion exchange model (described in Appendix 1) similar to that of Brouwer et al. (1983) and Poinssot et al. (1999) was applied to the adsorption data. In the mulitsite model, the adsorbed concentration is hypothesized to result from the contributions of sorption sites that differ in both affinity (e.g., high and low) and concentration. Previous multisite modeling of $\mathrm{Cs}^{+}$adsorption to illite rationalized these different sites as existing on the phyllosilicate basal plane and the frayed edge. The compositional dependence of the homovalent exchange $\left(\mathrm{Cs}^{+}-\mathrm{K}^{+}\right.$and $\left.\mathrm{Cs}^{+}-\mathrm{Na}^{+}\right)$was well approximated by a two-site model (Fig. 5) with site concentrations and exchange constants as summarized in Table 4. Modeling the heterovalent exchange $\left(\mathrm{Cs}^{+}-\mathrm{Ca}^{2+}\right)$ was more challenging and required five distinct sites to adequately fit the data (Fig. 5). A one-site model could not reproduce the sorption data from any electrolyte.

\section{5. $\mathrm{Cs}^{+}$Desorption}

The $\mathrm{K}^{+}$-induced release of adsorbed $\mathrm{Cs}^{+}$was evaluated at two different surface loadings ( $\log \mathrm{E}_{\mathrm{CsX}}=-0.521$ to -0.418 , and -2.09 to -2.04$)$ as a function of aging time (0.5-120 d) of the exchange complex (Table 5; see also arrows in Fig. 5b).
These different adsorption densities were achieved by contacting $\mathrm{Cs}^{+}\left(10^{-4} \mathrm{~mol} / \mathrm{L}\right)$ with the sediments in the presence of differing $\mathrm{Na}^{+}$concentrations $(0.005 \mathrm{~mol} / \mathrm{L}$ and $5.0 \mathrm{~mol} / \mathrm{L})$. The highest adsorption density was obtained with the lowest $\mathrm{Na}^{+}$ concentration $(0.005 \mathrm{~mol} / \mathrm{L})$. These adsorption densities are high and were chosen to be representative of sediments that had concentrated ${ }^{137} \mathrm{Cs}^{+}$from HLW through adsorption. Far lower surface concentrations of ${ }^{137} \mathrm{Cs}^{+}$occur in soils and sediments affected by bomb-test and Chernobyl fallout. In generating the samples for desorption study, it was observed that $\mathrm{Cs}^{+}$adsorption density was relatively constant with aging time in the concentrated electrolyte, but decreased with aging by a factor of $21.2 \%$ in the low concentration electrolyte (Table 5). This decrease may have resulted from the release of $\mathrm{K}^{+}$from orthoclase or mica.

Potassium induced the desorption of approximately 80-90\% of the adsorbed $\mathrm{Cs}^{+}$in low salt and $55-60 \%$ of the adsorbed $\mathrm{Cs}^{+}$in high salt (Fig. 6). The reversibly sorbed $\mathrm{Cs}^{+}$was immediately released after $\mathrm{K}^{+}$addition, with little additional $\mathrm{Cs}^{+}$release after $500 \mathrm{~h}$ more equilibration. There was no clear relationship between aging time and $\mathrm{Cs}^{+}$desorbability. The amount of $\mathrm{Cs}^{+}$that was resistant to $\mathrm{K}^{+}$displacement varied with initial surface loading and was approximately $9.0 \times 10^{-8}$ $\mathrm{mol} / \mathrm{g}$ in high salt and $1.98 \times 10^{-6} \mathrm{~mol} / \mathrm{g}$ in low salt. The 


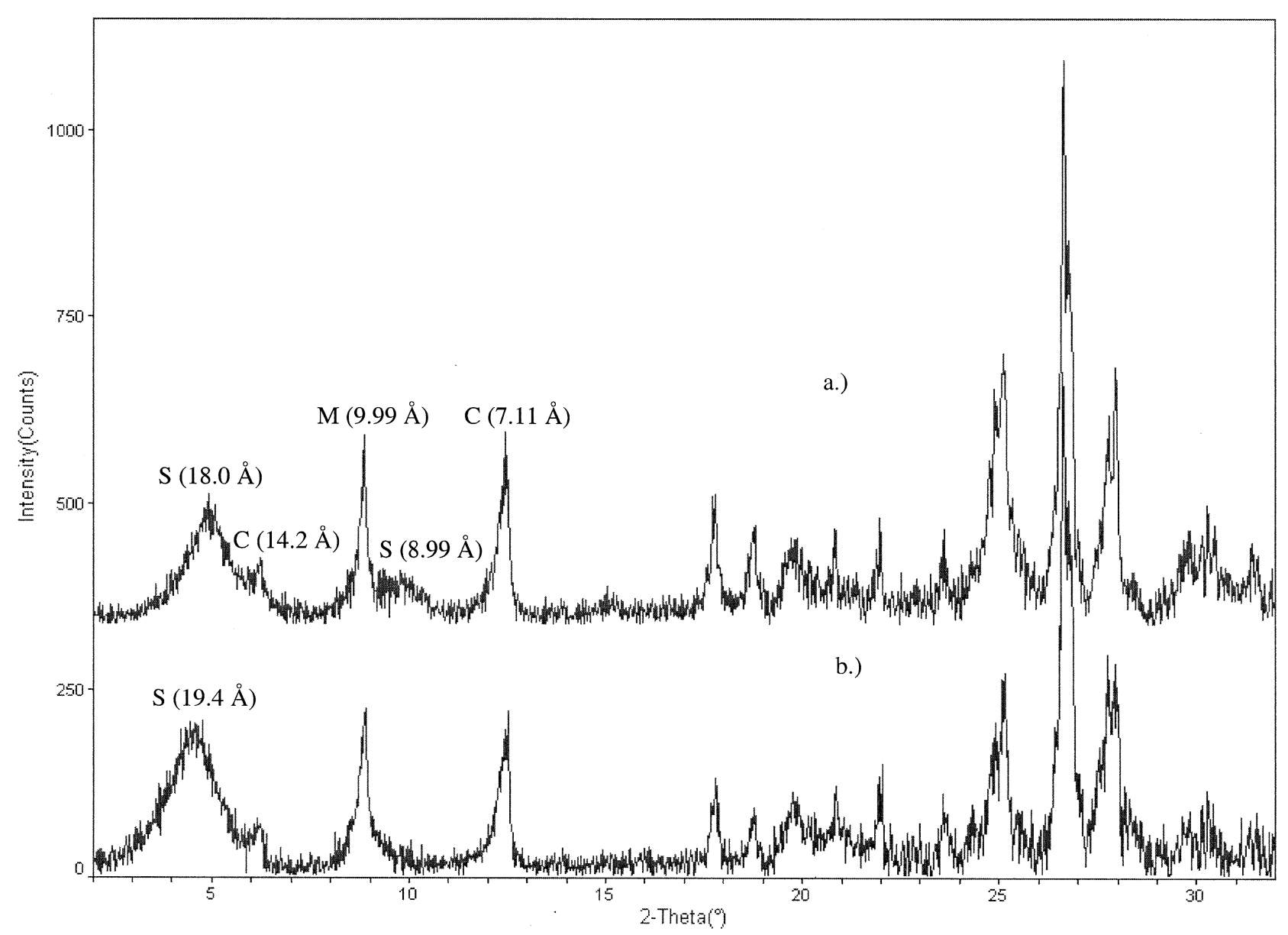

Fig. 3. XRD patterns of oriented samples of glycerol solvated, Mg-saturated clay $(<2.0 \mu \mathrm{m})$ from the Hanford sediment. (a) $110^{\circ} \mathrm{C}$; (b) $25^{\circ} \mathrm{C}$. S = smectite; $\mathrm{M}=$ mica; $\mathrm{C}=$ chlorite/clinochlore.

concentration of residual adsorbed $\mathrm{Cs}^{+}$was, therefore, a function of the initial electrolyte concentration and the adsorption density.

\subsection{Size Isolate and High Salt Studies}

Experiments were performed with two different size fractions $(<63 \mu \mathrm{m}, 125-250 \mu \mathrm{m})$ to assess whether high- and low-affinity sites were equally distributed in coarse- and finegrained materials. The low mass fraction of clay-sized materials $(<2 \%)$ prevented us from studying this fraction explicitly.

The coarse and fine fractions exhibited similar XRD patterns (Fig. 1), but the fines contained more smectite. The two materials exhibited comparable $\mathrm{Cs}^{+}$adsorption isotherms at low $(0.005 \mathrm{~mol} / \mathrm{L} \mathrm{Na})$ and high salt $(5 \mathrm{~mol} / \mathrm{L} \mathrm{Na})$ (Fig. 7). Cesium adsorption by the coarse fraction was consistently less than the fine fraction, reflecting its lower measured CEC in $\mathrm{Na}^{+}$electrolyte $\left(7.27 \times 10^{-5} \mathrm{eq} / \mathrm{g}\right.$ as compared to $\left.1.72 \times 10^{-4} \mathrm{eq} / \mathrm{g}\right)$. The comparable isotherm slopes of the coarse and fines indicated qualitatively similar site heterogeneity distributions.

As noted previously for the whole sediment, increasing $\mathrm{Na}^{+}$ (e.g., from $0.005 \mathrm{~mol} / \mathrm{L}$ to $5 \mathrm{~mol} / \mathrm{L}$ ) uniformly displaced the isotherms to lower sorption density (Fig. 4). The salt concen- tration was increased further here to $0.8 \times$ saturation with $\mathrm{NaNO}_{3(\mathrm{~s})}(7.0 \mathrm{~mol} / \mathrm{L})$. There was a small but significant difference between isotherms measured in 5 and $7 \mathrm{~mol} / \mathrm{L} \mathrm{Na}$ on the two size isolates (Fig. 7). The difference was more clearly manifest by the $\mathrm{K}_{\mathrm{d}}$ (Fig. 8). The $\mathrm{K}_{\mathrm{d}}$ plots showed that $\mathrm{Cs}^{+}$ adsorption on the low-affinity sites was swamped by high $\mathrm{Na}$ [e.g., $\mathrm{K}_{\mathrm{d}} \approx 0$ when $\log \mathrm{Cs}^{+}(\mathrm{eq} / \mathrm{g})>-7$ ]. The $\mathrm{Cs}^{+}$exchange to the high-affinity sites [e.g., $\log \mathrm{Cs}^{+}(\mathrm{eq} / \mathrm{g})<-7$ ] showed a decrease in $\mathrm{K}_{\mathrm{d}}$ that was proportional to the $\mathrm{Na}^{+}$increase, documenting mass action between $\mathrm{Cs}^{+}$and $\mathrm{Na}^{+}$on the highaffinity sites. The sizable differences in $K_{d}$ between the two size isolates at low $\mathrm{Cs}^{+}$-loading resulted from their different CECs.

The two size fractions yielded comparable $\mathrm{K}_{\mathrm{c}}$ values at 5.0 and $7.0 \mathrm{~mol} / \mathrm{L} \mathrm{Na}$ (Fig. 9), indicating that both fractions had identical distributions of high- and low-affinity sites within their cation exchange fractions. The $\mathrm{Na}^{+}-\mathrm{K}_{\mathrm{c}}$ function for the particle size isolates (Fig. 9) was almost identical to that for the whole sediment (Fig. 5b), and the two-site model again provided a reasonable match to the selectivity trend. The model parameters for the whole sediment yielded a small overprediction of the $\mathrm{K}_{\mathrm{c}}$ values for the particle isolates, that were improved upon by additional fitting (Fig. 9). The model parame- 

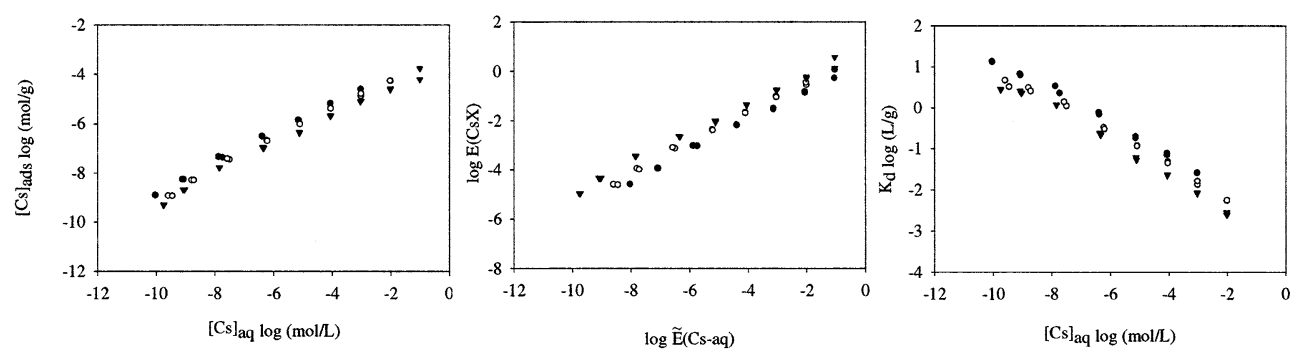

- $0.005 \mathrm{~mol} / \mathrm{L} \mathrm{Ca}\left(\mathrm{NO}_{3}\right)_{2} ; 2 \mathrm{~g} / \mathrm{L}$ Sediment

- $0.05 \mathrm{~mol} / \mathrm{L} \mathrm{Ca}\left(\mathrm{NO}_{3}\right)_{2} ; 2 \mathrm{~g} / \mathrm{L}$ Sediment

- $0.5 \mathrm{~mol} / \mathrm{L} \mathrm{Ca}\left(\mathrm{NO}_{3}\right)_{2} ; 5 \mathrm{~g} / \mathrm{L}$ Sediment
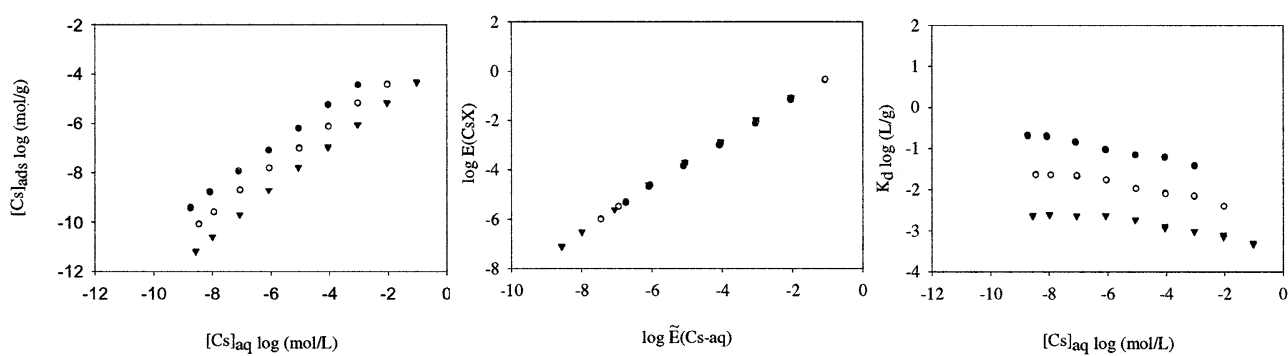

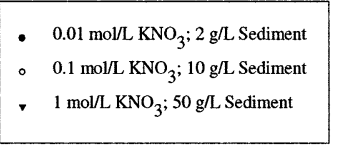
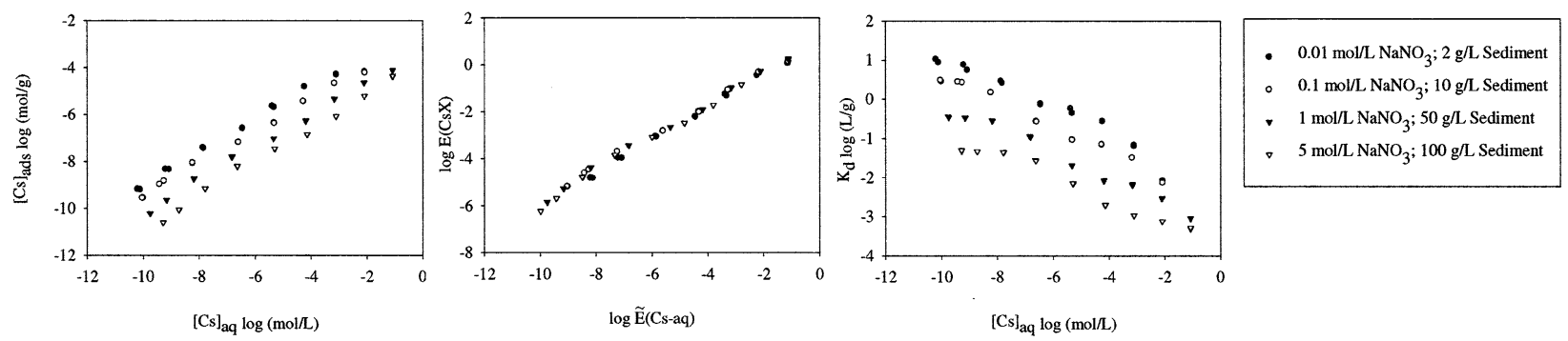

Fig. 4. $\mathrm{Cs}^{+}$adsorption data for the Hanford sediment in different electrolytes presented as isotherms $\left([\mathrm{Cs}]_{\mathrm{ads}}\right.$ vs. $\left.[\mathrm{Cs}]_{\mathrm{aq}}\right)$, exchange isotherms $[\mathrm{E}(\mathrm{CsX})$ vs. $\tilde{\mathrm{E}}(\mathrm{Cs}-\mathrm{aq})]$, and $\mathrm{K}_{\mathrm{d}}$ functions $\left(\mathrm{K}_{\mathrm{d}} \mathrm{vs} .[\mathrm{Cs}]_{\mathrm{aq}}\right)$.

ters for the different sites showed small differences from the whole soil that were attributed to experimental variance. The best-fit site concentrations for the high-affinity sites, $2.98 \times$ $10^{-8} \mathrm{eq} / \mathrm{g}$ and $7.05 \times 10^{-8} \mathrm{eq} / \mathrm{g}$ for the coarse and fine fractions respectively, are noted in Figure 9 . The $K_{d}$ values in high salt begin to increase at $\mathrm{Cs}^{+}$adsorption densities equal to and below those values.

\section{7. $\mathrm{Cs}^{+}$Adsorption with AgTU}

AgTU has been used to block planar exchange sites on soil phyllosilicates for quantification of the FES and their interac-

Table 3. Statistics of $\mathrm{Cs}^{+}$adsorption isotherm experiments.

\begin{tabular}{llc}
\hline & & $\begin{array}{c}\text { Average Relative Std Deviation } \\
(\%)\end{array}$ \\
\hline $\mathrm{Na}^{+}$ & $\mathrm{mol} / \mathrm{L}$ & 0.96 \\
& 5 & 0.83 \\
& 1 & 4.09 \\
$\mathrm{~K}^{+}$ & 0.1 & 2.49 \\
& 0.01 & 3.40 \\
$\mathrm{Ca}^{+}$ & 1 & 1.53 \\
& 0.1 & 2.23 \\
& 0.01 & 10.3 \\
Overall (10 exps) & 0.5 & 4.43 \\
& 0.05 & 2.21 \\
\end{tabular}

tion with $\mathrm{Cs}^{+}$(Cremers et al., 1988; De Preter et al., 1991). Selected experiments were performed here with AgTU to evaluate whether insights provided on the FES by the AgTU method were consistent with those derived from the multisite thermodynamic analysis in Figure 5.

The adsorption of $\mathrm{Cs}^{+}$in $0.015 \mathrm{~mol} / \mathrm{L} \mathrm{AgTU}$ exhibited an approach to saturation at $\left[\mathrm{Cs}^{+}\right]_{\mathrm{aq}} \approx 10^{-4} \mathrm{~mol} / \mathrm{L}$ (Fig. 10), yielding an operational estimate of the FES concentration $\left(\mathrm{FES}_{\mathrm{AgTU}}\right)$ of $7.94 \times 10^{-7} \mathrm{eq} / \mathrm{g}$. Although the sediment was not preequilibrated with AgTU before this measurement, the low solids concentration of the experiment $(2 \mathrm{~g} / \mathrm{L})$ and its attendent low site concentration $\left(\approx 8.52 \times 10^{-5} \mathrm{~mol} / \mathrm{L}\right)$ would have induced little change to the total aqueous concentration of AgTU through ion exchange. The $\mathrm{FES}_{\mathrm{AgTU}}$ was approximately $1.86 \%$ of the CEC in $\mathrm{Na}^{+}$electrolyte.

$\mathrm{A} \mathrm{Cs}^{+}$adsorption isotherm measured in presence of 0.015 $\mathrm{mol} / \mathrm{L} \mathrm{AgTU}$ and $0.1 \mathrm{~mol} / \mathrm{L} \mathrm{K}^{+}$showed close parity to one measured in $0.1 \mathrm{~mol} / \mathrm{L} \mathrm{K}^{+}$at low adsorbed $\mathrm{Cs}^{+}$concentration $\left(\log \mathrm{Cs}_{\mathrm{ads}}<-7.75 \mathrm{~mol} / \mathrm{g}\right.$; Fig. 10). Above this surface concentration, $\mathrm{Cs}^{+}$adsorption was slightly depressed by the AgTU, as compared to the $0.1 \mathrm{~mol} / \mathrm{L} \mathrm{K}^{+}$electrolyte alone. The adsorption of $\mathrm{Cs}^{+}$in the $0.015 \mathrm{~mol} / \mathrm{L} \mathrm{AgTU}$ and $0.1 \mathrm{~mol} / \mathrm{L} \mathrm{K}^{+}$ electrolyte exceeded the $\mathrm{FES}_{\mathrm{AgTU}}$. The $\mathrm{K}_{\mathrm{c}}$ values in presence of AgTU showed deviation (lower $\mathrm{K}_{\mathrm{c}}$ ) from $0.1 \mathrm{~mol} / \mathrm{L} \mathrm{K} \mathrm{K}^{+}$ electrolyte at low and high equivalent fraction values (Fig. 11a). The $\mathrm{CEC}_{\mathrm{K}}$ was used as the total site concentration. 

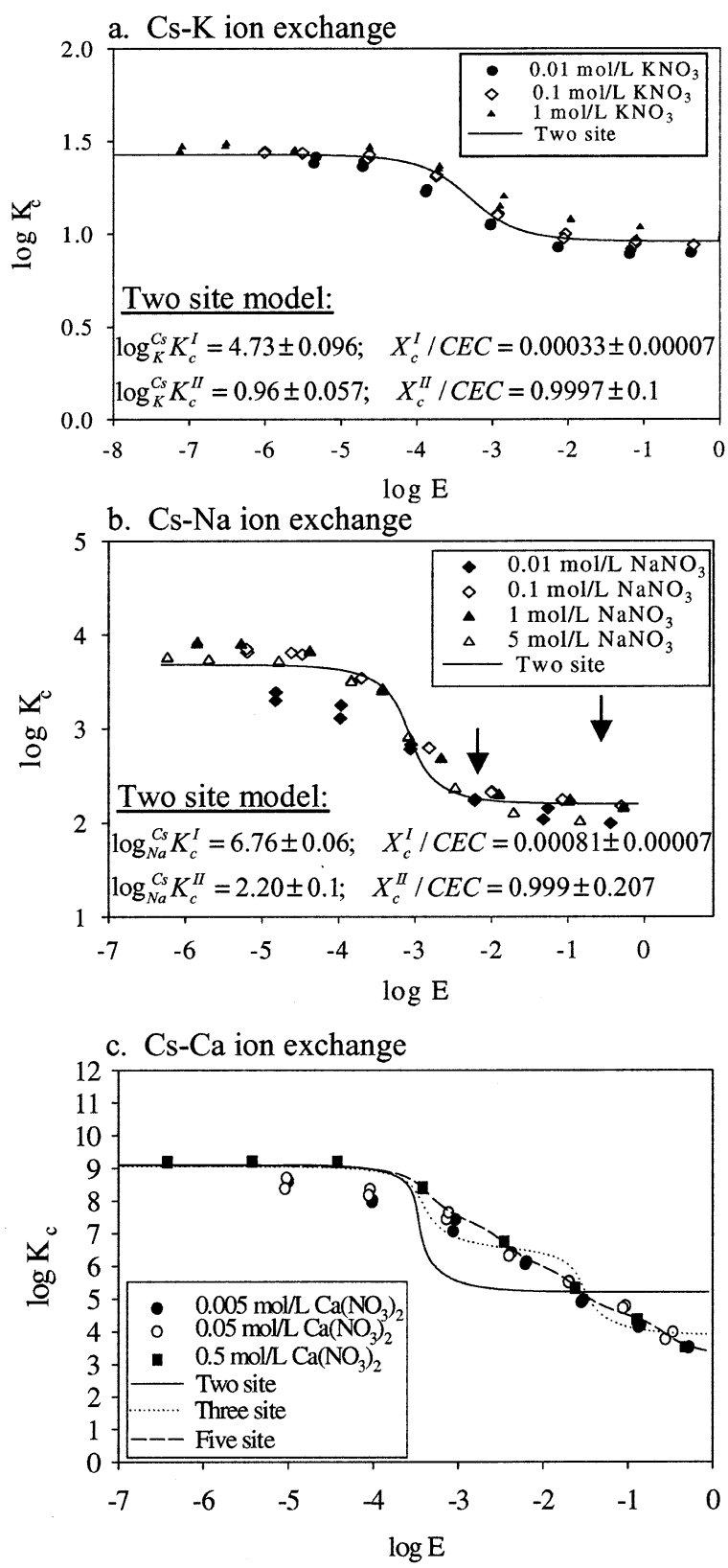

Two site:

$\log _{C a}^{C s} K_{c}^{I}=16.1 ; \quad X_{c}^{I} / C E C=0.00032$
$\log _{C s}^{C s} K_{c}^{I I}=5.2 ; \quad X^{I I} / C E C=0.9997$

Three site:

$\log { }_{C a}^{C s} K_{c}^{I}=16.0 ; \quad X_{c}^{I} / C E C=0.00032$

$\log { }_{C a}^{C s} K_{c}^{I I}=9.7 ; \quad X_{c}^{I I} / C E C=0.025$

$\log { }_{C a}^{C s} K_{c}^{I I I}=3.9 ; \quad X_{c}^{I I} / C E C=0.9747$

Five site:

$\log C_{C a}^{C_{S}} K_{c}^{I}=16.0 ; \quad X_{c}^{l} / C E C=0.00032$

$\log C_{C a}^{C_{s}} K_{c}^{I I}=12.5 ; \quad X_{c}^{I I} / C E C=0.002$

$\log { }_{C a}^{C_{s}} K_{c}^{I I I}=9.4 ; \quad X_{c}^{I I} / C E C=0.015$

$0 \log { }_{C a}^{C s} K_{c}^{N}=5.9 ; \quad X_{c}^{I I} / C E C=0.15$

$\log { }_{C a}^{C_{s}} K_{c}^{V}=3.3 ; \quad X_{c}^{I I} / C E C=0.8327$

Fig. 5. Computed conditional equilibrium constants $\left(\mathrm{K}_{\mathrm{c}}\right)$ from the adsorption data in Figure 4 , and results of multisite modeling (lines) as described in Appendix 1. Arrows in (b) define the adsorption densities of $\mathrm{Cs}^{+}$used in the desorption experiments of Figure 6.

Although the lowering of $\mathrm{K}_{\mathrm{c}}$ below $\log \mathrm{E}(\mathrm{CsX})$ of -5 was unexplained, the decrease in $\mathrm{K}_{\mathrm{c}}$ above $\log \mathrm{E}(\mathrm{CsX})=-4$ resulted from the competitive effect of AgTU for planar sites. This competition decreased, but did not eliminate, $\mathrm{Cs}^{+}$exchange to the planar sites.

The adsorption data of $\mathrm{Cs}^{+}$in the $0.015 \mathrm{~mol} / \mathrm{L} \mathrm{AgTU/0.1}$ $\mathrm{mol} / \mathrm{L} \mathrm{K}^{+}$electrolyte below an adsorption density of $10^{-6.35}$ was used to calculate $\mathrm{K}_{\mathrm{c}}^{\mathrm{FES}}$ using $\mathrm{FES}_{\mathrm{AgTU}}$ as the total site concentration (Fig. 11b). This figure is analogous to Fig. 3 in Cremers et al. (1988), and data from two of their soils that showed the highest (Soil 1) and lowest (Soil 3) affinity for $\mathrm{Cs}^{+}$ are reproduced for comparison. Cremers et al. (1988) attributed the rapid decrease in $\mathrm{K}_{\mathrm{c}}^{\mathrm{FES}}$ with increasing $\mathrm{Z}(\mathrm{Cs})\left(\mathrm{Cs}^{+}\right.$equivalent within the $\mathrm{FES}_{\mathrm{AgTU}}$ ) to the presence of two or more site types in the FES population. The results for the Hanford sediment differed from those of Cremers et al. (1988) in at least three ways: (1) a larger range of $\mathrm{Z}(\mathrm{Cs})$ was spanned by our data, (2) the intercept of $\mathrm{K}_{\mathrm{c}}^{\mathrm{FES}}$ as $\mathrm{Z}(\mathrm{Cs}) \rightarrow 0$ was higher as were all $\mathrm{K}_{\mathrm{c}}^{\mathrm{FES}}$ values, and (3) $\mathrm{K}_{\mathrm{c}}^{\mathrm{FES}}$ decreased to a lesser extent as $\mathrm{Z}(\mathrm{Cs})$ increased. The $\mathrm{K}_{\mathrm{c}}^{\mathrm{FES}}$ function for the Hanford sediment was bimodal, decreasing from $\mathrm{Z}(\mathrm{Cs})=0$ to 0.062 , and then was approximately level from $\mathrm{Z}(\mathrm{Cs})=0.062$ to 0.8 . The qualitative inflection point at $\mathrm{Z}(\mathrm{Cs})=0.062$ represented a $\mathrm{Cs}^{+}$ adsorption density of $4.92 \times 10^{-8} \mathrm{~mol} / \mathrm{g}$. This value was close 
Table 4. Summary of the parameters derived from the modeling of $\mathrm{Cs}^{+}$sorption data.

\begin{tabular}{lcccc}
\hline Ions & Site Type & $\mathrm{E}_{\mathrm{X}}{ }^{\mathrm{a}}$ & $\left(\log _{M}{ }^{C s^{+}} K_{c}\right)$ & $\Delta G(\mathrm{~kJ} / \mathrm{equiv})$ \\
\hline $\mathrm{Na}-\mathrm{Cs}$ & $\mathrm{I}$ & $0.00081 \pm 0.00007$ & $6.76 \pm 0.06$ & -38.6 \\
$\mathrm{Na-Cs}$ & II & $0.99912 \pm 0.207$ & $2.20 \pm 0.1$ & -12.6 \\
$\mathrm{~K}-\mathrm{Cs}$ & I & $0.00033 \pm 0.00007$ & $4.73 \pm 0.10$ & -27.0 \\
K-Cs & II & $0.99967 \pm 0.1$ & $0.96 \pm 0.06$ & -5.7 \\
$\mathrm{Ca}-\mathrm{Cs}$ & I & 0.00032 & 16.0 & -97.0 \\
\hline
\end{tabular}

${ }^{\text {a }}$ Equivalent fraction of CEC where $\mathrm{E}_{\mathrm{X}}=$ site concentration $(\mathrm{eq} / \mathrm{g}) / \mathrm{CEC}$.

to the fitted concentrations of the high-affinity sites in $\mathrm{Na}^{+}$ $\left(3.45 \times 10^{-8} \mathrm{~mol} / \mathrm{g}\right)$ and $\mathrm{K}^{+}\left(2.72 \times 10^{-8} \mathrm{~mol} / \mathrm{g}\right)$ electrolytes (Table 4).

The $\mathrm{Cs}^{+}-\mathrm{K}_{\mathrm{c}}$ values in the $0.015 \mathrm{~mol} / \mathrm{L} \mathrm{AgTU} / 0.1 \mathrm{~mol} / \mathrm{L} \mathrm{K}^{+}$ electrolyte (Fig. 11a) were modeled with the two-site model and the fitted parameters for $\mathrm{K}^{+}$electrolyte (Fig. 5a) to determine (1) whether the noted behavior was consistent with ternary exchange between $\mathrm{Cs}^{+}, \mathrm{K}^{+}$, and AgTU on planar sites, and (2) the best fit exchange coefficient for AgTU (e.g., Cs/ $\operatorname{AgTUK}_{\mathrm{c}}^{\mathrm{II}}$ ). The two-site model produced a reasonable description of the $\mathrm{K}_{\mathrm{c}}$ function (given experimental scatter), and its differences from the $\mathrm{K}^{+}$electrolyte, when ternary exchange was allowed on the planar site (site II) (fitted solid curve in Fig. 11a). The fitted Cs/AgTUK $\mathrm{c}_{\mathrm{c}}^{\mathrm{II}}$ was 0.63 , which significantly exceeded that reported by Cremers et al. (1988) for illite (0.022).

\subsection{Microscopy of $\mathrm{Cs}^{+}$-contacted Micas}

EMP elemental mapping was performed on $0.5-2.0-\mathrm{mm}$ mica flakes to identify the individual mica types responsible for selective $\mathrm{Cs}^{+}$adsorption (Fig. 12). Biotite and muscovite produced relatively sharp images of flake morphology, due to sharp, small-scale variations in $\mathrm{K}^{+}$concentration on the flake surfaces. Vermiculite, a biotite weathering product, showed a more uniform distribution of $\mathrm{K}^{+}$on the flake surface. Cesium distribution varied between the micas. On biotite, relatively large and abrupt variations in $\mathrm{Cs}^{+}$concentration were evident. Very intense concentrations of adsorbed $\mathrm{Cs}^{+}$were observed at selected areas on flake boundaries, and at surface zones of chemical alteration where wedge-type sites were most likely to occur. In some instances $\mathrm{Cs}^{+}$adsorption seemed to visually correlate with regions of $\mathrm{K}^{+}$depletion. On vermiculite, $\mathrm{Cs}^{+}$ was above the background level, but showed only subtle variation over the basal surface, without apparent concentration on the flake edge. There was no apparent correlation of $\mathrm{Cs}^{+}$ adsorption with structural features, or $\mathrm{K}^{+}$distribution. Muscovite also retained $\mathrm{Cs}^{+}$at low levels, with an average image intensity below that of vermiculite. Even at low loading levels, however, $\mathrm{Cs}^{+}$uptake was higher at flake edges than on the basal surface. Overall, however, the retention of $\mathrm{Cs}^{+}$on muscovite was the lowest of all three micaceous phases. Biotite, in contrast, exhibited the highest retention of $\mathrm{Cs}^{+}$. At least 5 or more particles of each of the above mica types was analyzed by EMP and all displayed $\mathrm{Cs}^{+}$distributions like those in Figure 12.

Previous research indicates that selective $\mathrm{Cs}^{+}$adsorption occurs along the frayed edges of micaceous particles. We tried repeatedly to obtain good cross-sectional images of the edge regions of biotite, apparently the strongest micaceous sorbent of $\mathrm{Cs}^{+}$, but the weathered edges of biotite were fragile and did

Table 5. Initial adsorbed $\mathrm{Cs}^{+}$concentrations in the $\mathrm{K}^{+}$-induced desorption experiment (Fig. 6).

\begin{tabular}{|c|c|c|}
\hline $\begin{array}{l}\text { Equilibration time } \\
\text { (d) }\end{array}$ & $\begin{array}{c}\text { Sorbed } \\
\text { Concentration } \\
\left(\mathrm{mol} / \mathrm{g} \times 10^{-6}\right)\end{array}$ & \\
\hline \multicolumn{2}{|c|}{$0.005 \mathrm{~mol} / \mathrm{L} \mathrm{Na}$ Electrolyte } & \multirow{10}{*}{ Range in $\log \mathrm{E}_{\mathrm{CsX}}=-.521$ to -.418} \\
\hline 0.5 & 16.25 & \\
\hline 1 & 14.79 & \\
\hline 4 & 13.48 & \\
\hline 10 & 14.30 & \\
\hline 20 & 13.88 & \\
\hline 30 & 13.34 & \\
\hline 60 & 12.98 & \\
\hline 120 & 12.81 & \\
\hline \multicolumn{2}{|c|}{$5.0 \mathrm{~mol} / \mathrm{L} \mathrm{Na}$ Electrolyte } & \\
\hline 0.5 & .366 & \multirow{8}{*}{ Range in $\log \mathrm{E}_{\mathrm{CsX}}=-2.09$ to -2.04} \\
\hline 1 & .344 & \\
\hline 4 & .359 & \\
\hline 10 & .389 & \\
\hline 20 & .351 & \\
\hline 30 & .388 & \\
\hline 60 & .359 & \\
\hline 120 & .376 & \\
\hline
\end{tabular}



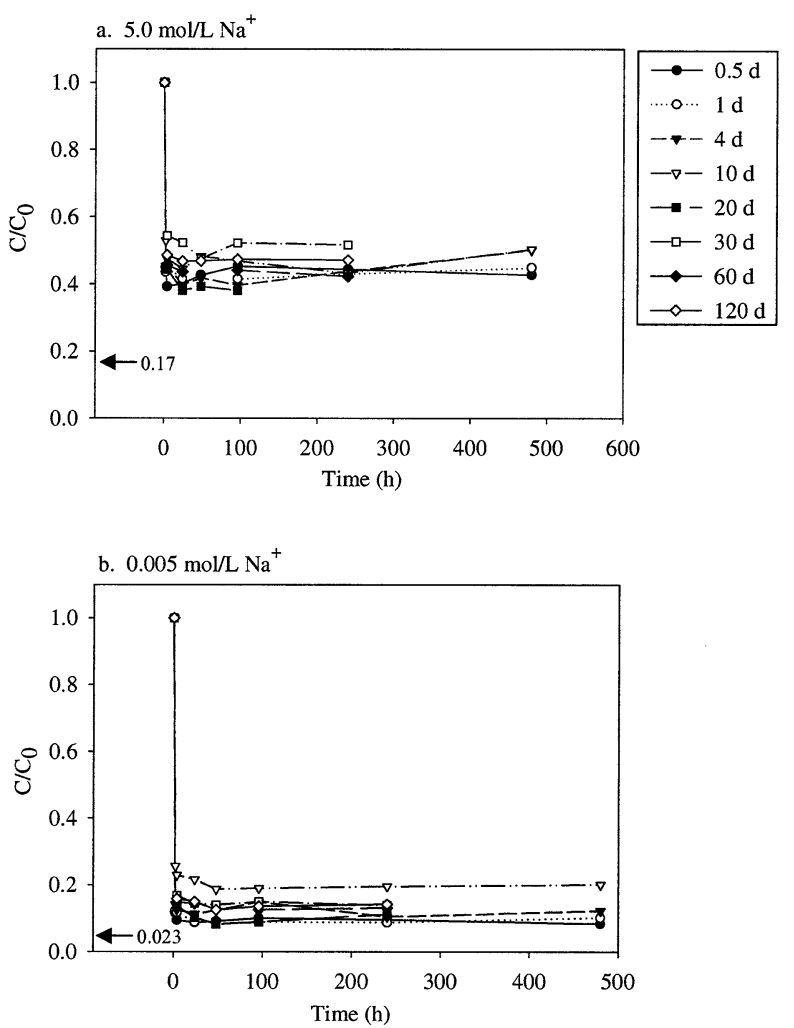

Fig. 6. Desorption of adsorbed $\mathrm{Cs}^{+}$(initial $\mathrm{Cs}^{+}=10^{-4} \mathrm{~mol} / \mathrm{L}$ ) by $\mathrm{K}^{+}\left(10^{-1} \mathrm{~mol} / \mathrm{L}\right)$ as a function of aging time of the sorption complex $(0.5-120 \mathrm{~d})$ and $\mathrm{K}^{+}$contact time $(1-500 \mathrm{~h})$. Arrows denote projected equilibrium concentrations computed with a ternary application $\left(\mathrm{Na}^{+}-\right.$ $\mathrm{K}^{+}-\mathrm{Cs}^{+}$) of the multisite model.

not hold up well to thin sectioning. Muscovite was more conducive to thin sectioning because of its low Fe content (Fig. 13). Muscovite exhibited a macroscopic region (e.g., ca. 150 $\mu \mathrm{m}$ ) of edge expansion or fraying (Fig. 13a). $\mathrm{Cs}^{+}$, however, adsorbed to only a few, selected areas in the macroscopic, frayed-edge region (Fig. 13b).

\section{DISCUSSION}

\subsection{Mineral Sorbents of $\mathrm{Cs}^{+}$}

The sorption process of $\mathrm{Cs}^{+}$in the Hanford sediment was one of ion exchange to different components of the phyllosilicate fraction. The phyllosilicate fraction contained both expansible (smectite, vermiculite) and nonexpansible (muscovite, biotite) 2:1 layer silicates (Figs. 1-3). The multisite modeling inferred the presence of two general site classes for $\mathrm{Cs}^{+}$in the $\mathrm{Na}^{+}$and $\mathrm{K}^{+}$saturated phyllosilicate fractions: (1) a highaffinity site class representing approximately 0.03 to $0.08 \%$ of the CEC, and (2) and a low-affinity site class representing greater than $99.9 \%$ of the CEC. In accord with past research (Cornell, 1993), we ascribe the high-affinity sites to the frayed edge regions on the nonexpansible micas (biotite, muscovite) and the low-affinity sites to planar exchange regions on the expansible clays (vermiculite, smectite). It is important to emphasize that the high-affinity sites exist at very low concentra-

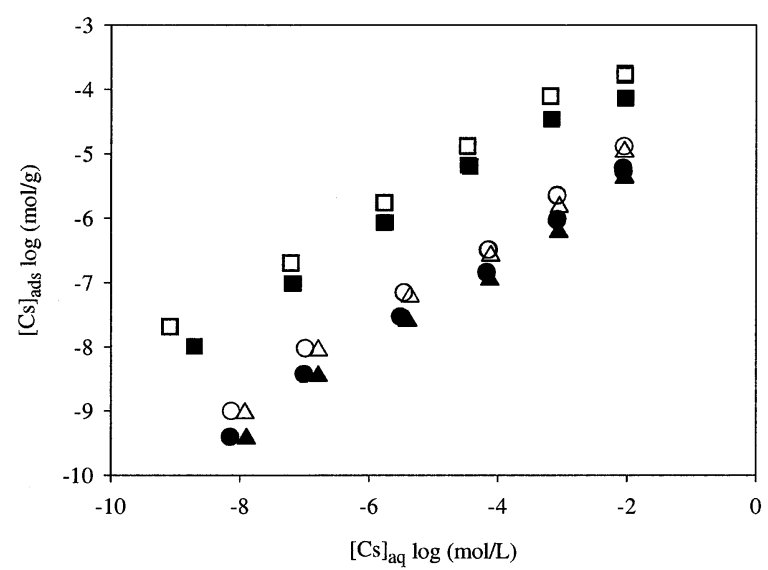

$$
\begin{array}{ll}
\square & <63 \mu \mathrm{m}, 5 \mathrm{~g} / \mathrm{L}, 0.005 \mathrm{~mol} / \mathrm{L} \mathrm{NaNO}_{3} \\
\square & 125-250 \mu \mathrm{m}, 10 \mathrm{~g} / \mathrm{L}, 0.005 \mathrm{~mol} / \mathrm{L} \mathrm{NaNO}_{3} \\
\mathrm{O} & <63 \mu \mathrm{m}, 100 \mathrm{~g} / \mathrm{L}, 5 \mathrm{~mol} / \mathrm{L} \mathrm{NaNO} \\
& 125-250 \mu \mathrm{m}, 250 \mathrm{~g} / \mathrm{L}, 5 \mathrm{~mol} / \mathrm{L} \mathrm{NaNO}_{3} \\
\triangle & <63 \mu \mathrm{m}, 100 \mathrm{~g} / \mathrm{L}, 7.0 \mathrm{~mol} / \mathrm{L} \mathrm{NaNO} \\
\Delta & 125-250 \mu \mathrm{m}, 250 \mathrm{~g} / \mathrm{L}, 7.0 \mathrm{~mol} / \mathrm{L} \mathrm{NaNO}_{3}
\end{array}
$$

Fig. 7. $\mathrm{Cs}^{+}$adsorption isotherms for two particle size isolates of the Hanford sediment $(<63 \mu \mathrm{m}$ and $125-250 \mu \mathrm{m})$ in $\mathrm{Na}^{+}$electrolytes of different concentration $(0.005,5.0$, and $7.0 \mathrm{~mol} / \mathrm{L})$.

tion (e.g., $2.72-3.45 \times 10^{-8} \mathrm{eq} / \mathrm{g}$ ), and identifying their mineralogic location is consequently difficult. Our fitted concentration of high-affinity or FES sites was below those previously reported for illites and soils which fall in the range of $0.5 \%$ of the CEC (Cornell, 1993; Cremers et al., 1988). Reasons for the apparently low FES concentration of the Hanford sediment may be our method of site concentration estimation (to be subsequently discussed) or that the micas are relatively unweathered. Muscovite was the dominant sediment mica and is the most resistant to weathering.

The ion microprobe study with millimeter-sized micas showed that biotite retained greater concentrations of $\mathrm{Cs}^{+}$than did muscovite or vermiculitized biotite under comparable conditions (Fig. 12). The enhanced sorptivity of biotite for $\mathrm{Cs}^{+}$ over muscovite contrasts with past studies (Dolcater et al., 1968; Torstenfelt et al., 1982) that concluded that dioctahedral micas (e.g., muscovite) have greater affinity for $\mathrm{Cs}^{+}$than trioctahedral micas (e.g., biotite) because of their higher layer charge density. We surmise, however, that weathering extent has played a key role in the Hanford sediment. Biotites extracted from the sediment showed a weathering aureole that was not evident for muscovite (Fig. 14). The weathered zone in the biotite was depleted in $\mathrm{K}^{+}$(Fig. 12), and was driven by the oxidation of structural $\mathrm{Fe}(\mathrm{II})$ with the concomitant decrease in layer charge density. While the edge region of muscovite was also weathered and frayed over the scale of tens of microns (Fig. 13), it is possible that the oxidative weathering of the biotite periphery was more conducive to formation of highaffinity, stereoselective regions for $\mathrm{Cs}^{+}$adsorption.

Sorption experiments with particle size isolates $(<63$ and 125-250 $\mu \mathrm{m}$, Figs. 7-9) were performed to evaluate two contrasting hypotheses on the physical and mineralogic nature of 

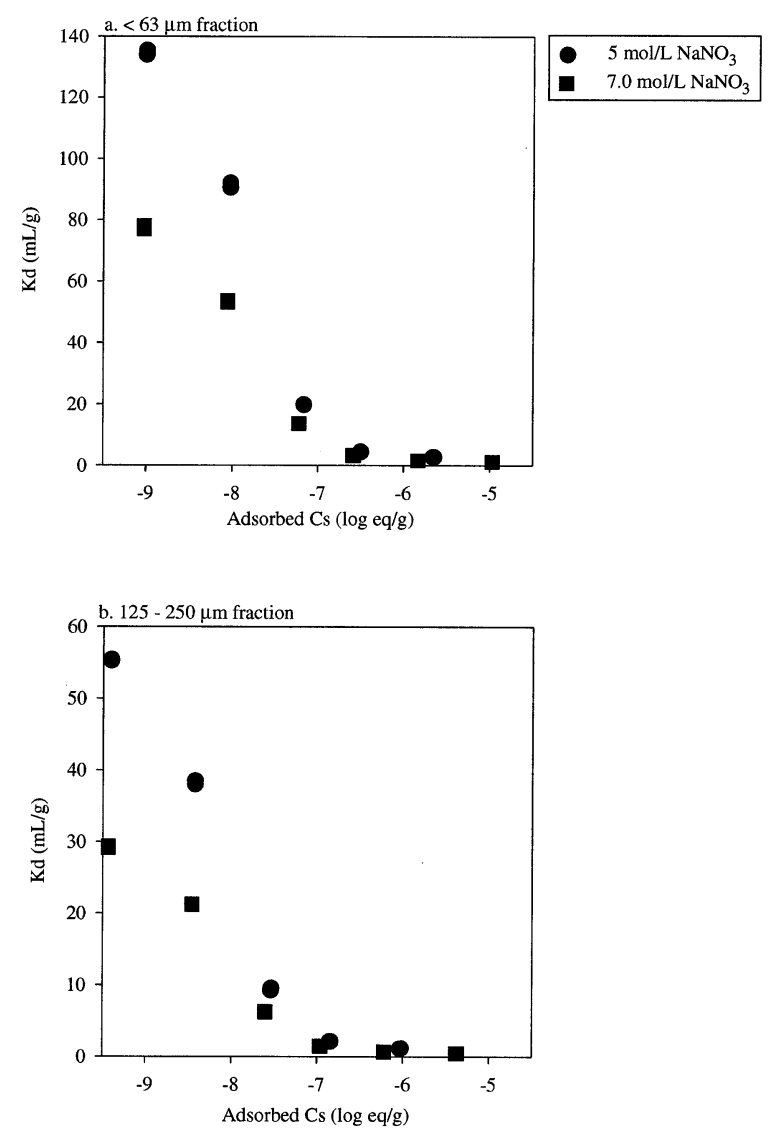

Fig. 8. Computed $\mathrm{Cs}^{+}$distribution coefficients $\left(\mathrm{K}_{\mathrm{d}}\right)$ for the high salt data (5.0 and 7.0 mol/L $\mathrm{NaNO}_{3}$ ) in Figure 7. (a) $<63 \mu \mathrm{m}$, (b) $125-250$ $\mu \mathrm{m}$.

the sorbing phases. In the first hypothesis, we speculated that high-affinity sites would be more abundant in the fine fraction because the edge surface area of the micaceous fraction and the extent of its chemical weathering would be proportionately higher. Previous reports by Zachara and Smith (1994) and Rajec et al. (1999) support this posit. In the second hypothesis, we speculated that high-affinity sites might be proportionally lower in the fine fraction, because the higher mass percent of smectite relative to the $10 \AA$ micaceous phase (Fig. 1) would lower the ratio of high-affinity sites to smectite-associated, low-affinity planar sites. In contrast to both these hypotheses, however, the apparent site distribution was independent of size fraction (Fig. 9). The high-affinity sites in both materials were less than $0.1 \%$ of the CEC. A significantly higher CEC was noted in the fine fraction (approximately 2.5 times the coarse fraction) consistent with its smaller grain size and smectite enrichment, but planar smectitic sites did not dilute highaffinity ones. In support of this observation we note that XRD showed micas to be ubiquitous in all sizes. The high-affinity sites were therefore present as a constant fraction of the CEC, regardless of particle size and attendant mineralogic variation.

\subsection{Multisite $\mathrm{Cs}^{+}$Adsorption Modeling}

As recently observed by Poinssot et al. (1999) for illite, we found that a two-site model could adequately describe $\mathrm{Cs}^{+}$ homovalent exchange to whole sediment and specific size fractions isolated from it. Our results were robust, spanning a large range in electrolyte and $\mathrm{Cs}^{+}$concentration, and site saturation. We had anticipated that a more complex model might be required because of the mineralogic complexity of the phyllosilicate fraction and the high ionic strength of the electrolyte solutions used. However, a model containing a generic high-affinity FES and a low-affinity planar site without explicit ion activity corrections for the aqueous cations or osmotic effects was found adequate. While we surmised that ion activity effects might cancel for the homovalent case, the weak ionicstrength dependence of the heterovalent exchange was unexpected.

The multisite modeling parameters for the Hanford sediment showed similarities and differences to the Le Puy (Poinssot et al., 1999) and Morris (Brouwer et al., 1983) illites (Table 6). The CEC of the Hanford sediment was a factor of 2-3 lower than the illites, as was the proportion of high-affinity sites, relative to the $\mathrm{CEC}$. $\mathrm{E}_{\mathrm{X} \text {-FES }}$ [where $\mathrm{E}_{\mathrm{X}}=$ site concentration $(\mathrm{X}) / \mathrm{CEC}]$ ranged from $3.3-8.1 \times 10^{-4}$ for the sediment and was $4.33 \times 10^{-3}$ for the Le Puy illite. This latter observation resulted from the presence of expansible clays in the Hanford sediment that diluted FES sites with planar ones. The selectivity coefficients for the high-affinity sites in both the sediment and the Le Puy illite were remarkably similar (Table 6). Both materials showed a surprisingly low preference of the FES for $\mathrm{K}^{+}$over $\mathrm{Na}^{+}$(e.g., $\log \mathrm{K}$ values ranging from 2.03 to 2.25 ), indicating that $\mathrm{Na}^{+}$may saturate the FES at high Na concentration. This mass action effect of $\mathrm{Na}^{+}$on $\mathrm{Cs}^{+}$exchange to the FES was most evident in Figure 8. Our value for $\mathrm{Cs}^{+}-\mathrm{Na}^{+}$ exchange on planar sites was $1.4 \mathrm{log}$ units below that of Poinssot et al. (1999), possibly because smectite was present in the sediment or because the exchange coefficients for the Le Puy illite were calculated using only $27.5 \%$ of the CEC sites (reason unknown). Selectivity coefficients calculated by Brouwer et al. (1983) for the planar sites on the Morris illite were below those for either the Hanford sediment or the Le Puy illite.

Unlike the $\mathrm{Na}^{+}$and $\mathrm{K}^{+}$electrolytes, the $\mathrm{Cs}^{+}$sorption data in $\mathrm{Ca}^{2+}$ electrolyte could not be described with a two-site model (Fig. 5c). Five sites were required to fit the $\mathrm{Cs}^{+}-\mathrm{Ca}^{2+} \mathrm{K}_{\mathrm{c}}$ function. These sites included a high-affinity site with total concentration $\left(1.5 \times 10^{-8} \mathrm{eq} / \mathrm{g}\right)$ similar to that fitted in $\mathrm{Na}^{+}$ electrolyte $\left(1.36 \times 10^{-8} \mathrm{eq} / \mathrm{g}\right)$, and four planar sites of varying selectivity. Whether these fitting parameters have physical/ chemical basis is not clear. It is known that as a divalent cation with large hydration energy, $\mathrm{Ca}^{2+}{ }_{(\mathrm{aq})}$ can induce quasicrystal formation of the expansible clays (smectite primarily; Shainberg and Kaiserman, 1969; Shomer and Mingelgrin, 1978; Schramm and Kwak, 1982) that contribute to the planar sorption capacity of the sediment for $\mathrm{Cs}^{+}$. Sposito (1984) summarized data from many sources and concluded that the average number of unit smectite layers found in face-to-face association was 4-8 in $\mathrm{Ca}^{2+}$ electrolyte and 3 in $\mathrm{Cs}^{+}$electrolyte. Quasicrystals of divalent cations (e.g., $\mathrm{Ca}^{2+}, \mathrm{Mg}^{2+}$ ) may resist heterovalent exchange until a critical concentration of the monovalent cation is reached (Verburg et al., 1995). It is plausible that the smectitic fraction of the Hanford sediment underwent quasicrystal formation during $\mathrm{Ca}^{2+}$ saturation. Varied structural microenvironments may have existed in the in- 


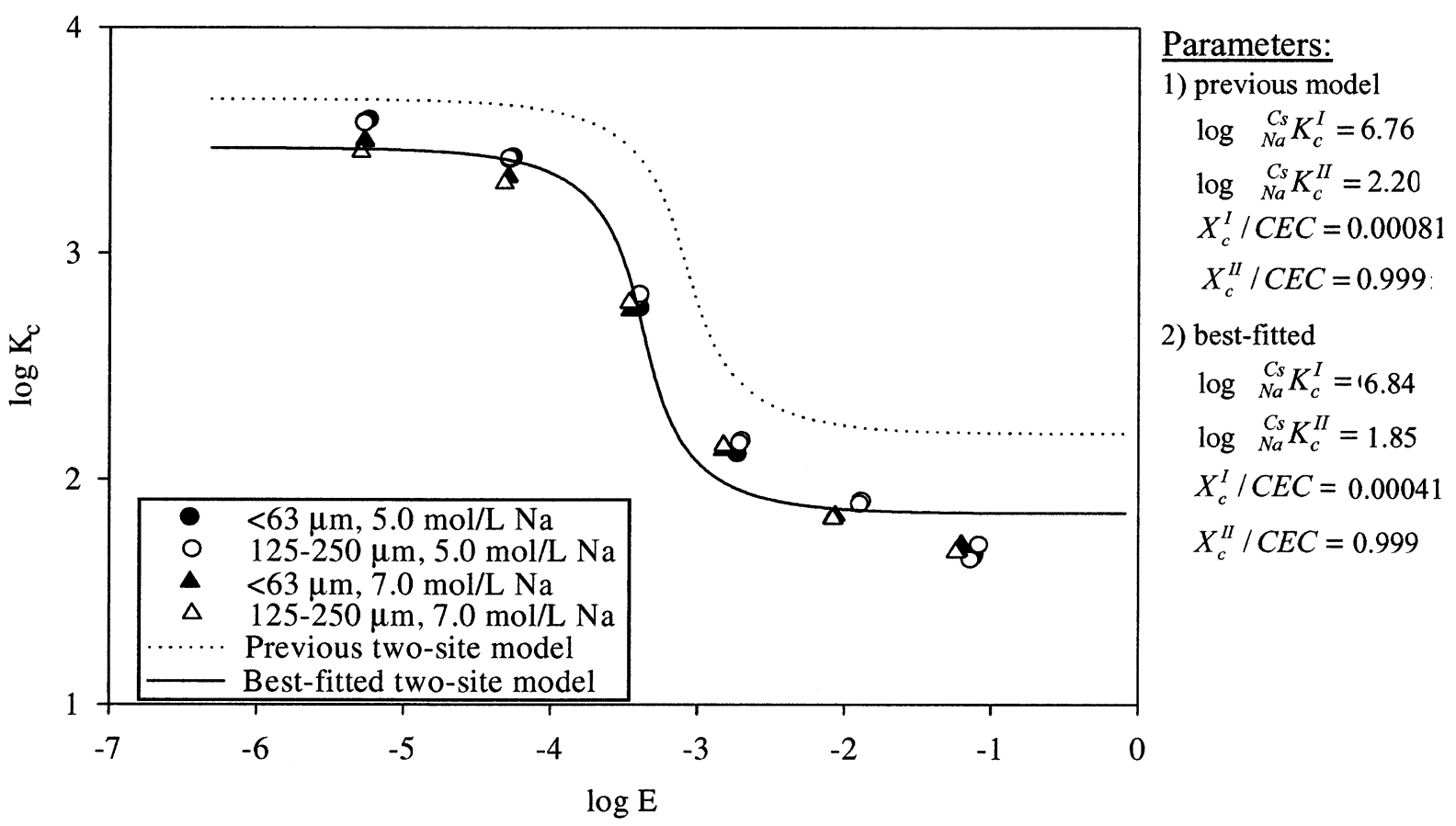

Fig. 9. Computed conditional equilibrium constants $\left(\mathrm{K}_{\mathrm{c}}\right)$ for $\mathrm{Cs}^{+}$adsorption to particle size isolates in high salt solutions (5.0 and $7.0 \mathrm{~mol} / \mathrm{L} \mathrm{NaNO}_{3}$ ) and multisite model calculations using parameters from the whole sediment (Fig. 5) and best fit values.

terlayer sites of these quasicrystals that exhibit different exchange selectivities for $\mathrm{Cs}^{+}$.

An unresolved issue in the multisite modeling was that of the total site concentration or the CEC. Different CECs were measured in the different electrolytes (Table 2), with the $\mathrm{K}^{+}$ electrolyte CEC almost twice that of either $\mathrm{Na}^{+}$or $\mathrm{Ca}^{2+}$ electrolyte. These differences were substantiated through repeat measurements. An explanation for this large difference was not established. These CECs were used as the electrolyte-specific total site concentrations for modeling purposes. However, in both $\mathrm{Na}^{+}$and $\mathrm{Ca}^{2+}$ electrolyte, the maximum $\mathrm{Cs}^{+}$adsorption density exceeded the CEC (Table 2). The data points that exceeded the electrolyte-specific CEC were not used in the sorption modeling of Figure 5 because their equivalent fractions computed to be greater than 1 . We initially speculated that a class of sites may exist in the sediment with high $\mathrm{K}^{+}-\mathrm{Na}^{+}$ selectivity that resisted replacement in $\mathrm{Na}^{+}\left(\right.$or $\mathrm{Ca}^{2+}$ ) electrolyte. However, the observation of a relatively low preference of the high-affinity sites for $\mathrm{K}^{+}$over $\mathrm{Na}^{+}$(Table 6) brings that hypothesis into question.

\subsection{Desorption of Adsorbed $\mathrm{Cs}^{+}$}

The adsorption of $\mathrm{Cs}^{+}$by mineral solids involves a rapid ion exchange reaction that occurs within minutes to hours, and a slower component often termed "fixation" where $\mathrm{Cs}^{+}$is transferred to less available sites (Comans et al., 1991; Smith and Comans, 1996). The long-term sorption process apparently involved intraparticle diffusion to or within microfissures and dehydrated interlamellar space, as well as collapse of the FES (Lomenick and Tamura, 1965; Klobe and Gast, 1970; Le Roux et al., 1970), and leads to a sorbed fraction that displays slowly reversible behavior (Comans et al., 1991; Smith and Comans, 1996). The time constant of the slow reaction has been measured for both illite and aquatic sediments, being approximated with a half-life $\left(\mathrm{t}_{1 / 2}\right)$ of $100 \mathrm{~d}$. Studies with laboratory spiked (Lomenick and Tamura, 1965) and field-contaminated sediments at tracer concentrations (Evans et al., 1983; Comans et al., 1989; Smith and Comans, 1996; McKinley et al., 2000) indicate that the "fixed" or poorly reversible fraction increases with age of the sorption complex, and the content of micaceous sorbents. The desorbable fraction of $\mathrm{Cs}^{+}$in 15-20-year-old contaminated sediments from Oak Ridge, Tennessee and the Savannah River Plant ranged from $1 \%$ to $20 \%$ depending on sediment provenance and mineralogy (Evans et al., 1983). However, the poorly reversible fraction appears fully exchangeable with the aqueous phase given sufficiently long time periods (Cornell, 1993; Smith and Comans 1996), and sorbed $\mathrm{Cs}^{+}$may be remobilized if bathing aqueous fluids become enriched in competitive cations such as $\mathrm{NH}_{4}^{+}$and $\mathrm{K}^{+}$(Evans et al., 1983; Comans et al., 1989; Smith and Comans, 1996).

Here, we investigated the desorbability of $\mathrm{Cs}^{+}$from the $\mathrm{Na}^{+}$-saturated Hanford sediment at two different surface loadings (Fig. 6) corresponding to full saturation of the high-affinity sites with half-saturation of the planar sites $\left(\mathrm{Na}^{+}=0.005\right.$ mol/L, Fig. 5b), and approximate full saturation of the highaffinity sites $\left(\mathrm{Na}^{+}=5.0 \mathrm{~mol} / \mathrm{L}\right.$, Fig. $\left.5 \mathrm{~b}\right)$. These were relatively high surface leadings that were chosen because of our focus on HLW interactions. Additionally the sorption complex was allowed to age for time periods (up to $120 \mathrm{~d}$ ) that exceeded the reported time constant for the fixation reaction $\left(t_{1 / 2}=100 \mathrm{~d}\right.$, 


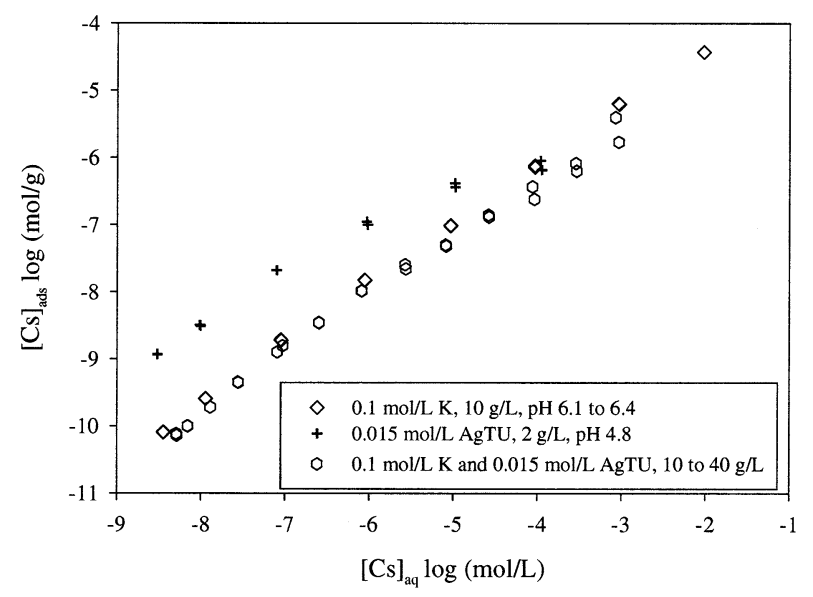

Fig. 10. Adsorption isotherms of $\mathrm{Cs}^{+}$on the Hanford sediment in presence of $0.015 \mathrm{~mol} / \mathrm{L} \mathrm{AgTU}, 0.1 \mathrm{~mol} / \mathrm{L} \mathrm{K}^{+}$and $0.015 \mathrm{~mol} / \mathrm{L} \mathrm{AgTU}$, and $0.1 \mathrm{~mol} / \mathrm{L} \mathrm{K}^{+}$.

Smith and Comans, 1996) in an attempt to qualitatively determine the importance of the slow sorption process. Desorption was induced by $\mathrm{K}^{+}$addition at a 1000 -fold excess. Ternary exchange calculations were performed to predict the equilibrium $\mathrm{C} / \mathrm{C}_{0}$ after $\mathrm{K}^{+}$displacement using the multisite model, the parameters listed in Table 5 for the $\mathrm{Na}^{+}$-saturated sediment, the solid-to-solution ratios of the desorption experiment at different time points, and the total experimental concentrations of $\mathrm{Na}^{+}$, $\mathrm{K}^{+}$, and $\mathrm{Cs}^{+}$.

As shown in Figure 6 (note arrows), the predicted $C / \mathrm{C}_{0}$ values were below the experimentally observed values for both adsorption densities. The disparity was much larger for the sample loaded in high salt (e.g., $5.0 \mathrm{~mol} / \mathrm{L} \mathrm{Na}^{+}$, Fig. 6a). While several factors involving experimental and parameter uncertainty may be evoked to explain the difference between the equilibrium prediction and the experimental observation, the results implied that a fraction of the adsorbed $\mathrm{Cs}^{+}$was poorly exchangeable or "fixed." This fraction ranged between $10 \%$ for high sorption density to $25 \%$ for low sorption density samples.

The poorly exchangeable concentration in the high salt sample was $4.82 \times 10^{-8} \mathrm{~mol} / \mathrm{g}$, which was on parity with the computed FES concentration $\left(3.41 \times 10^{-8} \mathrm{~mol} / \mathrm{g}\right)$. A larger quantity of sorbed $\mathrm{Cs}^{+}\left(\approx 1.5 \times 10^{-6} \mathrm{~mol} / \mathrm{g}\right)$ was poorly exchangeable in the high sorption density sample (equilibrated in low salt). This concentration exceeded the FES and included $\mathrm{Cs}^{+}$adsorbed to planar sites. The amount of poorly exchangeable $\mathrm{Cs}^{+}$on the planar sites represented approximately $3.5 \%$ of the total planar site concentration fitted by modeling (Table 6 ). Collapse of vermiculite and smectite interlayers induced by sorbed $\mathrm{Cs}^{+}$or the high $\mathrm{KNO}_{3}$ desorption solution may explain this poorly reversible fraction (Sawhney, 1972). Surprising aspects of this apparent fixation at both adsorption densities were that it occurred almost immediately after $\mathrm{Cs}^{+}$addition, its extent did not appear to correlate with aging time of the sorption complex $(0.5$ to $120 \mathrm{~d})$, and its reversibility was negligible even after $500 \mathrm{~h}$ of contact with excess $\mathrm{K}^{+}$. These findings are similar to those observed for the Fithian illite where instantaneous fixation of adsorbed $\mathrm{Cs}^{+}$occurred when excess $\mathrm{NH}_{4}^{+}(1 \mathrm{~mol} / \mathrm{L})$ was used as a desorbing electrolyte (R. N. J. Comans, private communication). Comans concluded that this fixation was an artifact of the high $\mathrm{NH}_{4}^{+}$ that induced collapse of the $\mathrm{Cs}^{+}$-containing FES. Whether the desorption results shown here for the Hanford sediment are similarly artifactual remains to be determined. Our results, however, agree, in part, with $\mathrm{Cs}^{+}$desorption experiments with 30-yr-old HLW-contaminated Hanford sediments where only a small amount of the sorbed $\mathrm{Cs}^{+}$could be desorbed using
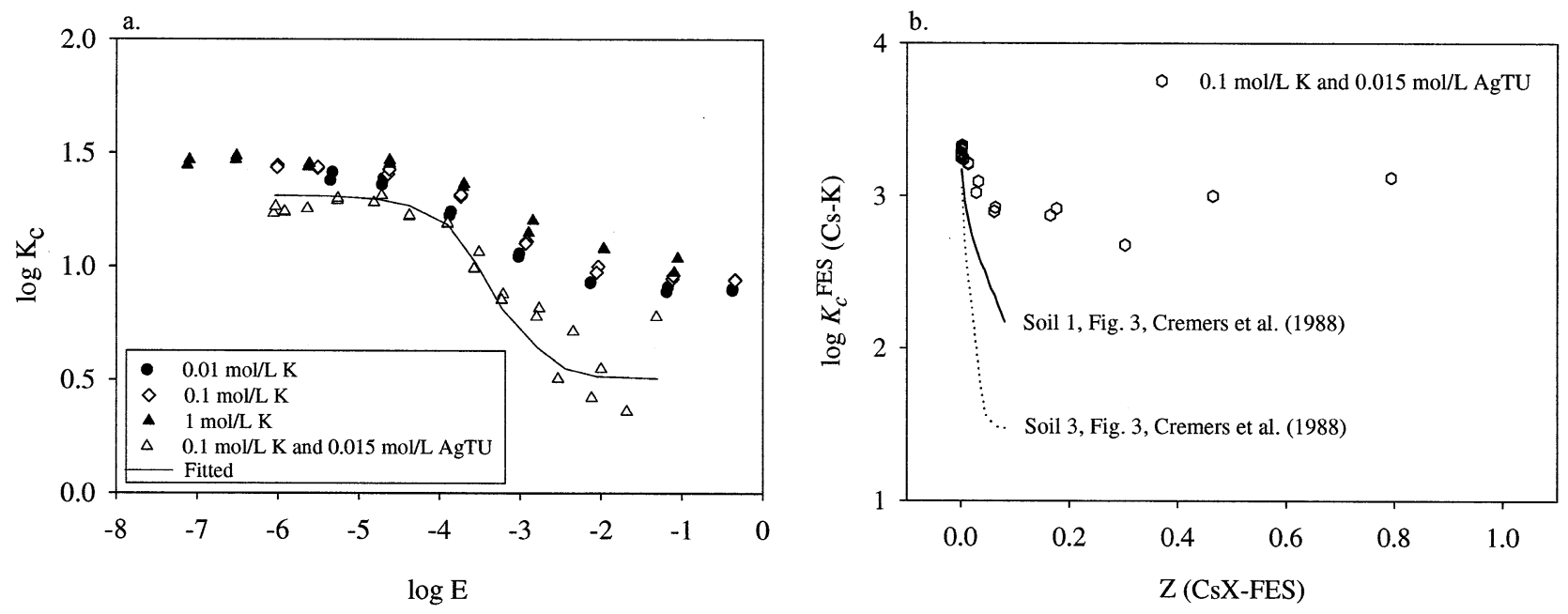

Fig. 11. (a) Conditional equilibrium constants $\left(\mathrm{K}_{\mathrm{c}}\right)$ for $\mathrm{Cs}^{+}$in $\mathrm{K}^{+}$electrolyte computed using $\mathrm{CEC}_{\mathrm{K}}$ as the total site concentration showing impact of AgTU. The $\mathrm{K}_{\mathrm{c}}$ function in presence of AgTU was fit using multisite parameters for the whole sediment from Figure 5 and a $\mathrm{Cs}^{+}$-AgTU exchange constant on the planar sites of 0.63 as described in Appendix 2. (b) Conditional equilibrium constants for the FES $\left(\mathrm{K}_{\mathrm{c}}^{\mathrm{FES}}\right)$ calculated using the extrapolated sorption maximum in 0.015 $\mathrm{mol} / \mathrm{L}$ as the operational FES concentration $\left(\mathrm{FES}_{\mathrm{AgTU}}\right)$. Shown for comparison are data from two soils studied by Cremers et al., 1988. A change in slope occurs at $\mathrm{Z}(\mathrm{CsX}-\mathrm{FES}) \approx 0.075$ which equals a Cs ${ }^{+}$adsorption density of $4.8 \times 10^{-8} \mathrm{~mol} / \mathrm{g}$. 
a. Biotite
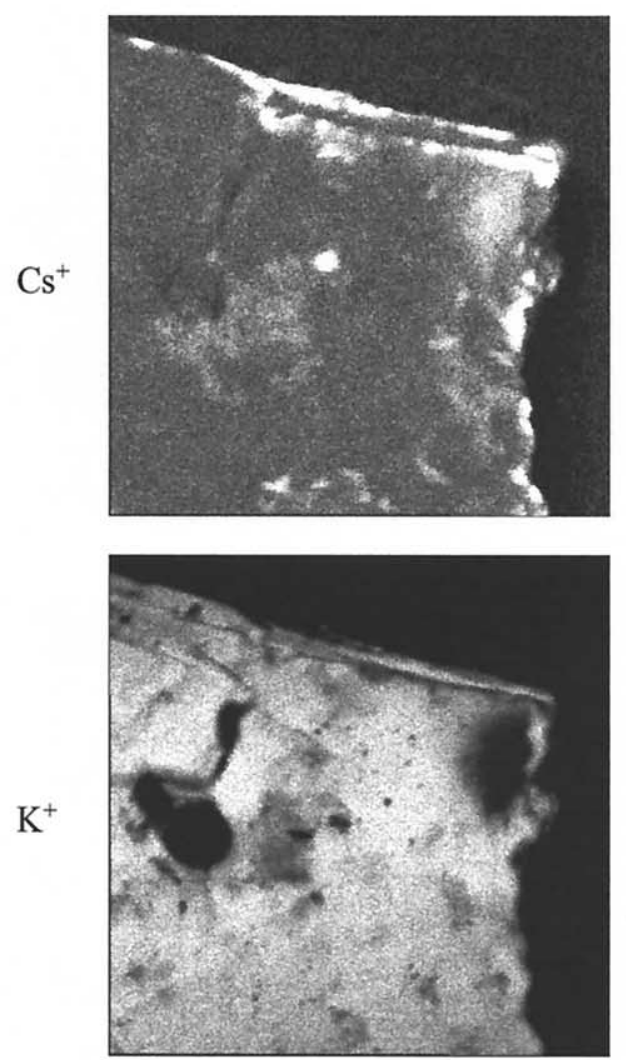

b. Vermiculitized Biotite
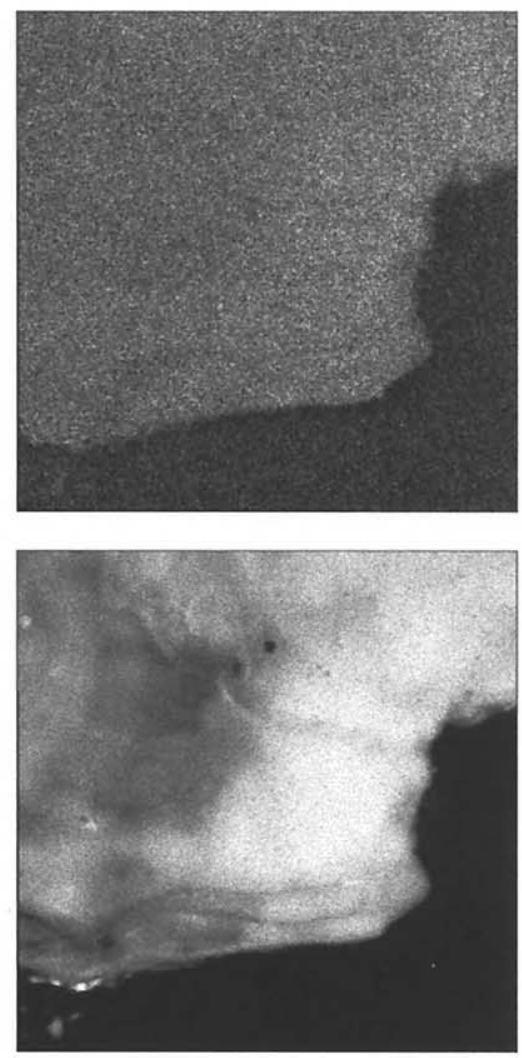

c. Muscovite
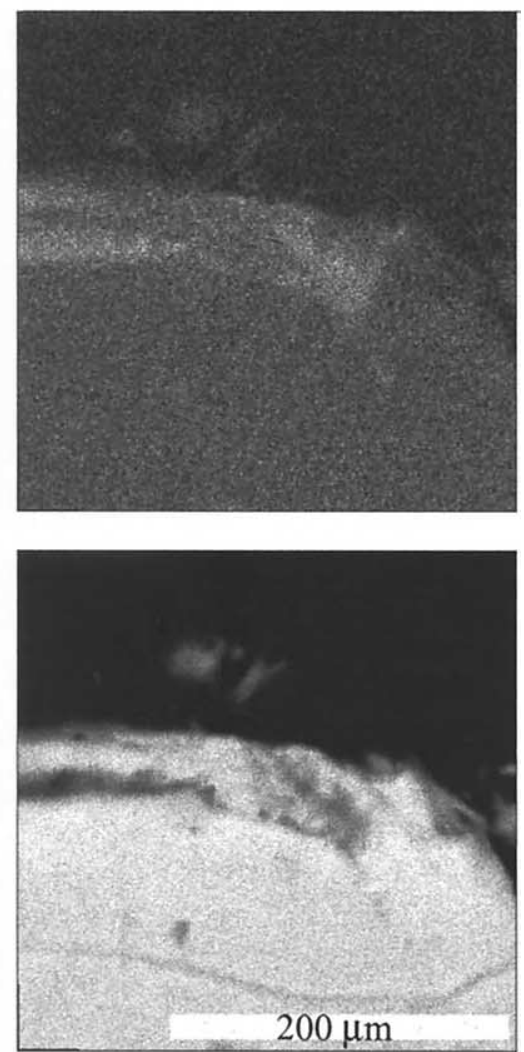

Fig. 12. Plan-view (parallel to c) EMP images of $\mathrm{Cs}^{+}$-contacted, hand-picked micas $(0.5-2.0 \mathrm{~mm})$ from the Hanford sediment. The upper three panels show the $\mathrm{Cs}^{+}$distribution in biotite, vermiculitized biotite, and muscovite, and the lower three panels show $\mathrm{K}^{+}$distribution. Scale as noted.

the most aggressive treatments (McKinley et al., 2000), including acid dissolution.

\subsection{Consistency of the AgTU Method}

The AgTU blocking procedure has been used to isolate and characterize the FES, and to estimate in situ $\mathrm{K}_{\mathrm{d}}$ values at trace $\mathrm{Cs}^{+}$concentration (Cremers et al., 1988; De Preter et al., 1991). In practice, we found the technique to be difficult to perform due to the unstable chemical nature of AgTU, and difficult to interpret for reasons to be described below. We performed additional experiments with AgTU and variable $\mathrm{K}^{+}$ and $\mathrm{Na}^{+}$as recommended by De Preter et al., (1991), but those experiments were deemed uninterpretable and were not reported herein.

We found two primary problems with the AgTU method. First, the FES site concentration estimated by the isotherm extrapolation procedure in $0.015 \mathrm{~mol} / \mathrm{L} \mathrm{AgTU}\left(\mathrm{FES}_{\mathrm{AgTU}}=\right.$ $7.94 \times 10^{-7} \mathrm{eq} / \mathrm{g}$ ) was markedly higher than that estimated through multisite modeling $\left(2.72-3.45 \times 10^{-8} \mathrm{eq} / \mathrm{g}\right)$. Thus, AgTU did not block all planar sites, and sites that exhibited $\mathrm{Cs}^{+}$selectivity comparable to planar ones were included in the FES $_{\text {AgTU }}$ pool. This phenomenon, which may result from restricted access of the bulky AgTU cation to planar sites on vermiculite, gives the mistaken impression that the FES themselves exhibit multisite selectivity for $\mathrm{Cs}^{+}$. The use of the
FES $_{\mathrm{AgTU}}$ as the total site concentration also influences the computed value of the FES exchange coefficients through its influence on the exchanger phase equivalent fraction. In contrast, an FES population approximated by uni-site selectivity was more consistent with results of the sorption modeling. A second problem was that $\mathrm{Cs}^{+}$was more competitive with AgTU on planar sites of the Hanford sediment than reported on illite. Multisite modeling of the ternary sorption experiment with $\mathrm{Cs}^{+}, \mathrm{K}^{+}$, and AgTU yielded a best fit $\mathrm{K}_{\mathrm{c}}^{\mathrm{II}}$ for $\mathrm{Cs}^{+}$-AgTU exchange of 0.63 , which compared to 0.022 for illite (Cremers et al., 1988). Because AgTU is only slightly preferred over $\mathrm{Cs}^{+}$ by the planar sites, AgTU is not an effective blocking agent of the planar sites at intermediate and higher $\mathrm{Cs}^{+}$concentrations. $\mathrm{Cs}^{+}$may populate a fraction of the planar sites in spite of the presence of AgTU.

The AgTU method was developed to provide insights on the sorption chemistry of $\mathrm{Cs}^{+}$at trace levels. Our results suggest that it must be applied with care to trace $\mathrm{Cs}^{+}$levels because of its tendency to overestimate the FES concentration. De Koning et al. (2001) have recently shown that the presence of vermiculite complicates the use of the AgTU method to estimate the FES concentration. Collapse of vermiculite interlayers apparently occurs with the high $\mathrm{Cs}^{+}$concentrations needed to saturate the FES. This collapse creates additional high-affinity sites for $\mathrm{Cs}^{+}$adsorption, leading to an overestimate in the FES 
a. $\mathrm{K}^{+}$

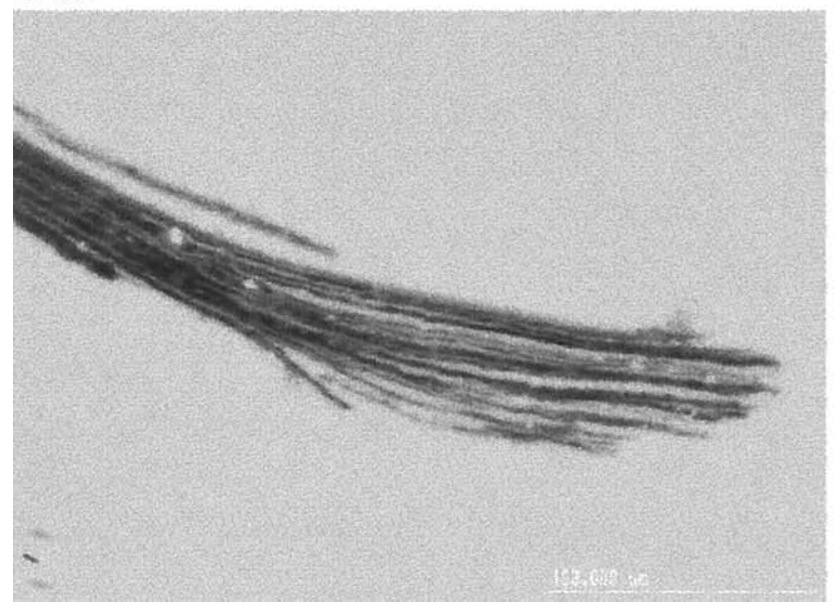

b. $\mathrm{Cs}^{+}$

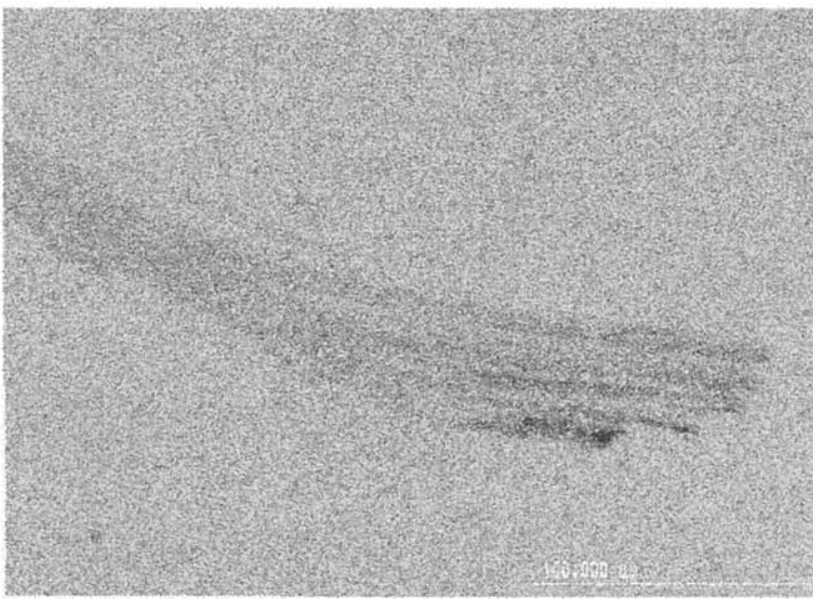

Fig. 13. Cross-sectional EMP image (normal to c) of $\mathrm{Cs}^{+}$and $\mathrm{K}^{+}$distribution in Cs-contacted Hanford muscovite showing macroscopic edge fraying and localized regions of $\mathrm{Cs}^{+}$adsorption.

concentration unless specific precautions are taken. The Hanford sediment contains vermiculite as an accessory phyllosilicate (Fig. 2), and it is possible that vermiculite collapse may have contributed to the high FES concentration estimated by the AgTU procedure $\left(7.94 \times 10^{-7} \mathrm{eq} / \mathrm{g}\right)$. Furthermore, the application of the AgTU method to higher $\mathrm{Cs}^{+}$concentrations is questionable due to complex ternary exchange behavior that may occur on all or a fraction of the planar sites. Overall, it is an erroneous simplification to state that AgTU blocks all planar sites, and that the unblocked ones are high-affinity sites for $\mathrm{Cs}^{+}$. We temper these conclusions with recognition that they are based on comprehensive study of only one subsurface sediment that may, in fact, exhibit anomalous behavior.

\subsection{Implications to Subsurface HLW Migration}

The extraction of $\mathrm{Pu}$ from irradiated uranium fuels generated large volumes of highly radioactive waste materials that have

a.

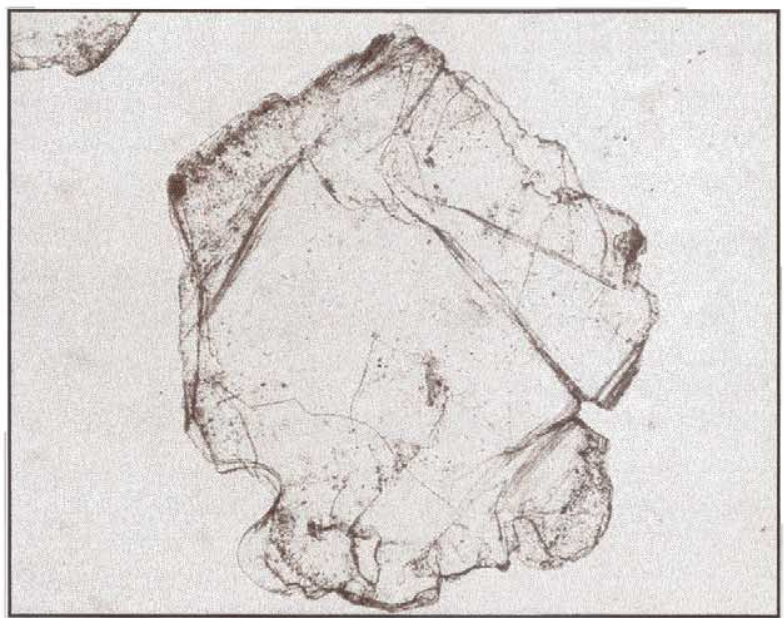

been stored at U.S. Department of Energy (DOE) facilities awaiting long-term disposal. Most of the U.S. HLW are stored at the Hanford Site in Washington State in 162 massive underground tanks, each ranging in size from 55,000 to 1.1 million gallons. The HLW are complex and variable in composition. A common feature of the Hanford tank wastes is the presence of high concentrations (greater than $0.5 \mathrm{~mol} / \mathrm{L}$ ) of $\mathrm{Na}^{+}$and $\mathrm{NO}_{3}^{-}$/ $\mathrm{NO}_{2}^{-}$, among other chemical constituents. ${ }^{137} \mathrm{Cs}$ represents approximately $40 \%$ of the total radioactivity of the tanks; it is highly soluble and is found primarily in the supernatant at concentrations ranging up to $0.4-0.5 \mathrm{Ci} / \mathrm{L}\left(0.005 \mathrm{~mol}{ }^{137} \mathrm{Cs} / \mathrm{L}\right)$. Given the fission product production of other $\mathrm{Cs}^{+}$isotopes, the total mass concentration of $\mathrm{Cs}^{+}$is about three times this value.

Sixty-seven HLW tanks at Hanford have leaked, discharging over 1 million gallons of HLW supernate and over 1 million $\mathrm{Ci}$ of ${ }^{137} \mathrm{Cs}$ to the vadose zone. To a large degree, the ${ }^{137} \mathrm{Cs}$ has been strongly sorbed by the Hanford sediment studied herein,

b.

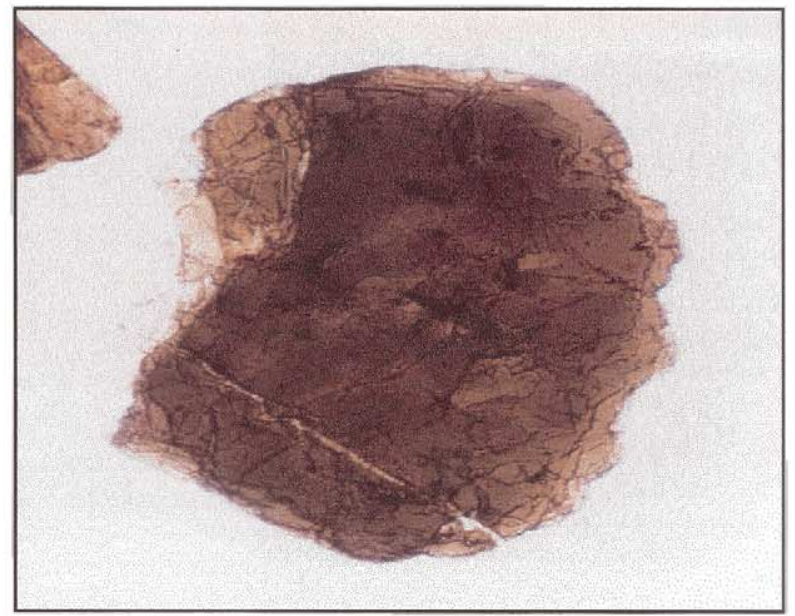

Fig. 14. Optical micrographs of hand-picked muscovite (a) and biotite (b) from the Hanford sediment. Biotite shows a distinct aureole of weathering around its periphery and near fractures. 
Table 6. Multiple site modeling parameters for $\mathrm{Cs}^{+}$sorption by illite and the Hanford sediment.

\begin{tabular}{|c|c|c|c|c|}
\hline \multirow[b]{2}{*}{ Citation } & \multirow[b]{2}{*}{ Site Type } & \multicolumn{2}{|c|}{ Site Concentration } & \multirow{2}{*}{$\begin{array}{c}\text { Selectivity Coefficient } \\
\left(\log K_{c}\right)\end{array}$} \\
\hline & & $X^{a}$ & $\mathrm{Ex}^{\mathrm{b}}$ & \\
\hline Brouwer et al., (1983) & $\begin{array}{l}\text { FES (type 1) } \\
\text { FES (type 2) } \\
\text { Planar }\end{array}$ & $\begin{aligned} \mathrm{CEC}_{\mathrm{Na}} & =1.53 \times 10^{-4} \mathrm{eq} \\
1.0 & \times 10^{-6} \mathrm{eq} / \mathrm{g}(\mathrm{Na}) \\
5.0 & \times 10^{-7} \mathrm{eq} / \mathrm{g}(\mathrm{K}) \\
5.0 & \times 10^{-6} \mathrm{eq} / \mathrm{g}(\mathrm{Na}) \\
5.0 & \times 10^{-6} \mathrm{eq} / \mathrm{g}(\mathrm{K})\end{aligned}$ & $\begin{array}{c}2.00 \times 10^{-4} \mathrm{eq} / \mathrm{g} \\
6.53 \times 10^{-3} \\
2.53 \times 10^{-3} \\
3.26 \times 10^{-2} \\
2.53 \times 10^{-2} \\
0.999 \\
0.999\end{array}$ & $\begin{aligned} \mathrm{Na}-\mathrm{Cs} & =5.64 \\
\mathrm{~K}-\mathrm{Cs} & =4.08 \\
\mathrm{Na}-\mathrm{Cs} & =2.99 \\
\mathrm{~K}-\mathrm{Cs} & =1.38 \\
\mathrm{Na}-\mathrm{Cs} & =1.56 \\
\mathrm{~K}-\mathrm{Cs} & =0.65\end{aligned}$ \\
\hline Poinssot et al., (1999) & $\begin{array}{l}\text { FES } \\
\text { Planar }\end{array}$ & $\begin{array}{l}\mathrm{CEC}_{\mathrm{Na}}=1 . \\
5.5 \times 10^{-7} \mathrm{eq} / \mathrm{g} \\
3.5 \times 10^{-5} \mathrm{eq} / \mathrm{g}\end{array}$ & $\begin{array}{l}\mathrm{q} / \mathrm{g} \\
4.33 \times 10^{-3} \\
2.75 \times 10^{-1 \mathrm{~d}}\end{array}$ & $\begin{aligned} \mathrm{Na}-\mathrm{Cs} & =6.95 \pm 0.2 \\
\mathrm{~K}-\mathrm{Cs}^{\mathrm{e}} & =4.70 \\
\mathrm{Na}-\mathrm{K} & =2.25 \pm 0.4 \\
\mathrm{Na}-\mathrm{Cs} & =3.60 \pm 0.2\end{aligned}$ \\
\hline This study (from Fig. 5) & Planar & $\begin{array}{c}\mathrm{CEC}_{\mathrm{Na}}=4.26 \times 10^{-5} \mathrm{eq} \\
3.45 \times 10^{-8} \mathrm{eq} / \mathrm{g}(\mathrm{Na}) \\
2.72 \times 10^{-8} \mathrm{eq} / \mathrm{g}(\mathrm{K}) \\
\\
4.26 \times 10^{-5} \mathrm{eq} / \mathrm{g}(\mathrm{Na}) \\
8.25 \times 10^{-5} \mathrm{eq} / \mathrm{g}(\mathrm{K})\end{array}$ & $\begin{array}{c}8.25 \times 10^{-5} \mathrm{eq} / \mathrm{g} \\
8.1 \times 10^{-4} \\
3.3 \times 10^{-4} \\
\\
0.999 \\
0.999\end{array}$ & $\begin{aligned} \mathrm{Na}-\mathrm{Cs} & =6.76 \pm 0.6 \\
\mathrm{~K}-\mathrm{Cs} & =4.73 \pm .10 \\
\mathrm{Na}-\mathrm{K}^{\mathrm{f}} & =2.03 \\
\mathrm{Na}-\mathrm{Cs} & =2.20 \pm .1 \\
\mathrm{~K}-\mathrm{Cs} & =0.96 \pm .057 \\
\mathrm{Na}-\mathrm{K}^{\mathrm{f}} & =1.24\end{aligned}$ \\
\hline
\end{tabular}

${ }^{a}$ total concentration.

${ }^{\mathrm{b}} \mathrm{Ex}=$ site concentration/ $\mathrm{CEC}_{\mathrm{M}}$, where $\mathrm{M}$ is the electrolyte cation.

${ }^{c} \mathrm{~K}_{\mathrm{c}}=\frac{\mathrm{E}_{\mathrm{CsX}}\left[\mathrm{M}^{+}\right]}{\mathrm{E}_{\mathrm{MX}}\left[\mathrm{Cs}^{+}\right]}$, where $\mathrm{E}=$ equivalent fraction and $\mathrm{M}$ is electrolyte cation.

d note planar sites $<<$ CEC.

e by difference.

f by difference.

limiting vertical migration to distances of approximately 7-32 $\mathrm{m}$. Sorption has concentrated radiocesium in the sediments, and contaminated samples have been retrieved from beneath the tanks with ${ }^{137} \mathrm{Cs}$ activities as high as $10^{8} \mathrm{pCi} / \mathrm{g}$. Such samples are so radioactive they require $5.1 \mathrm{~cm}$ of lead shielding surrounding a $5.1-\mathrm{cm}$ steel split-spoon sampler for safe handling. This radioisotopic concentration corresponds to an absolute concentration of $8.43 \times 10^{-9} \mathrm{~mol}{ }^{137} \mathrm{Cs} / \mathrm{g}$, which represents approximately $24.4 \%$ of the FES capacity (or $\sim 75 \%$ when accounting for other $\mathrm{Cs}^{+}$isotopes) of the Na-saturated sediment estimated by the multisite modeling.

In selected locations beneath tanks that have leaked ${ }^{137} \mathrm{Cs}$ in hot $\mathrm{NaNO}_{3(\mathrm{~s})}$-saturated brines (e.g., $\mathrm{Na}^{+}>10 \mathrm{~mol} / \mathrm{L}$ ), $\mathrm{Cs}^{+}$has experienced little apparent retardation [e.g., $\mathrm{K}_{\mathrm{d}}(\mathrm{ml} / \mathrm{g})<1$ ] and has migrated to greater depths than expected. The analysis of subsurface cores from these locations has shown the presence of elevated concentration of $\mathrm{Ca}^{2+}, \mathrm{Mg}^{2+}$, and $\mathrm{K}^{+}$preceding the $\mathrm{Na}^{+}$pulse at depth as a result of their global displacement by high $\mathrm{Na}^{+}$. The experimental and modeling results presented herein allow us to conclude that the expedited migration of ${ }^{137} \mathrm{Cs}$ observed in this rather harsh environment results from the competitive effect (on both planar and FES sites) of the massive $\mathrm{Na}^{+}$concentration, further exentuated by the displacement of exchangeable $\mathrm{K}^{+}$at the leading edge of the migrating HLW front. We are evaluating this conclusion using transport calculations and the multisite modeling parameters developed in this study. The HLW also contain high concentrations of other ions, most notably $\mathrm{OH}^{-}$and $\mathrm{Al}(\mathrm{OH})_{4}^{-}$, that could influence the migration of ${ }^{137} \mathrm{Cs}$ through dissolution and precipita- tion reactions. These latter effects will be the subject of forthcoming publications.

Acknowledgment-Research was supported by the U.S. Department of Energy (DOE), Environmental Management Sciences Program (EMSP). Pacific Northwest National Laboratory is operated for the DOE by Battelle Memorial Institute under Contract DE-AC06-76RLO 1830. Appreciation is extended to geologists Bruce Bjornstad and George Last (PNNL) who assisted us in obtaining sediment samples representative of those beneath the S-SX tank farm at Hanford. A. de Koning and R. N. J. Comans are acknowledged for their thoughtful and detailed review of this manuscript and for sharing soon-to-be-published results on $\mathrm{Cs}^{+}$desorption from illite and the influence of vermiculite on FES quantification by the AgTU method. Their comments led to a greatly improved manuscript.

Associate editor: D. L. Sparks

\section{REFERENCES}

Babcock K. L. and Schulz R. K. (1970) Isotopic and conventional determination of exchangeable sodium percentage of soil in relation to plant growth. Soil Sci. 109, 19-22.

Brouwer E., Baeyens B., Maes A., and Cremers A. (1983) Cesium and rubidium ion equilibria in illite clay. J. Phys. Chem. 87, 1213-1219.

Comans R. N. J. and Hockley D. E. (1992) Kinetics of cesium sorption on illite. Geochim. Cosmochim. Acta 57, 1157-1164.

Comans R. N. J., Haller M., and De Preter P. (1991) Sorption of cesium on illite: Non-equilibrium behavior and reversibility. Geochim. Cosmochim. Acta 55, 433-440.

Comans R. N. J., Middelburg J. J., Zonderhula J., Wolttiez J. R. W., De Lange G. J., Das H. A., and Van Der Weijden C. H. (1989) Mobilization of radiocaesium in pore water of lake sediments. Nature 339, 367-369. 
Cornell R. M. (1993) Adsorption of cesium on minerals: A review. $J$. Radioanal. Nucl. Chem. 171, 483-500.

Cremers A., Elsen A., De Preter P., and Maes A. (1988) Quantitative analysis of radiocesium retention in soils. Nature 335, 247-249.

de Koning A., Konoplev A. V., and Comans R. N. J. (2001) Measuring the specific cesium sorption capacity of soils, sediments and clay minerals. Water Res. (in press).

De Preter P., Van Loon L., Maes A., and Cremers A. (1991) Solid/ liquid distribution of radiocesium in boom clay: A quantitative interpretation. Radiochim. Acta 52/53, 299-302.

Dolcater D. L., Lotse E. G., Syers J. K., and Jackson M. L. (1968) Cation exchange selectivity of some clay-sized minerals and soil materials. Soil Sci. Soc. Am. Proc. 32, 795-798.

Evans D. W., Alberts J. J., and Clark R. A. III (1983) Reversible ion-exchange fixation of cesium-137 leading to mobilization from reservoir sediments. Geochim. Cosmochim. Acta 47, 1041-1049.

Francis C. W. and Brinkley F. S. (1976) Preferential adsorption of $137 \mathrm{Cs}$ to micaceous minerals in contaminated freshwater sediment. Nature 260, 511-513.

Grant S. A. and Fletcher P. (1993) Chemical thermodynamics of cation exchange reactions. Ion Exchange and Solvent Extraction 11, 1-108.

Grütter A., von Gunten H. R., Kohler M., and Rössler E. (1990) Sorption, desorption and exchange of cesium on glaciofluvial deposits. Radiochim. Acta 50, 177-184.

IMSL. (1991) International Math and Statistics Library, Math Library, Houston, TX.

Jackson M. L. (1963) Interlaying of expansible layer silicates in soils by chemical weathering. Clays Clay Miner. 11, 29-46.

Kemner K. M., Hunter D. B., Bertsch P. M., Kirkland J. P., and Elam W. T. (1997) Determination of site-specific binding environments of surface sorbed cesium on clay minerals by Cs-EXAFS. J. Phys. IV France 7, 777-779.

Kim Y., Cygan R. T., and Kirkpatrick R. J. (1996) ${ }^{133}$ Cs NMR and XPS investigation of cesium adsorbed on clay minerals and related phases. Geochim. Cosmochim. Acta 60, 1041-1052.

Klobe W. D. and Gast R. G. (1970) Conditions affecting cesium fixation and sodium entrapment in hydrobiotite and vermiculite. Soil Sci. Soc. Am. Proc. 34, 746-750.

Le Roux J., Rich C. I., and Ribbe P. H. (1970) Ion selectivity by weathered micas as determined by electron microprobe analysis. Clays Clay Miner. 18, 333-338.

Lomenick T. F. and Tamura T. (1965) Naturally occurring fixation of cesium-137 on sediments of lacustrine origin. Soil Sci. Soc. Proc. Amer. 29, 383-387.

McKinley J. P., Serne R. J., Zachara J. M., Zeissler C. J., and Lindstrom R. M. (2001) The distribution and retention of ${ }^{137} \mathrm{Cs}$ in sediments beneath leaked waste tanks at the Hanford Site, Washington. Environ. Sci. Technol. 35, 3433-3441.

Poinssot C., Baeyens B., and Bradbury M. H. (1999) Experimental and modeling studies of cesium sorption on illite. Geochim. Cosmochim. Acta 63, 3217-3227.

Rajec P., Sucha V., Eberl D. D., Srodon J., and Elsass F. (1999) Effect of illite particle shape on cesium sorption. Clays Clay Miner. 47, 755-760.

Rich C. I. and Black W. R. (1964) Potassium exchange as affected by cation size, pH, and mineral structure. Soil Sci. 97, 384-390.

Sawhney B. L. (1970) Potassium and cesium ion selectivity in relation to clay mineral structure. Clays Clay Miner. 18, 47-52.

Sawhney B. L. (1972) Selective sorption and fixation of cations by clay minerals. Clays Clay Miner. 20, 93-100.

Serne R. J., Zachara J. M., and Burke D. S. (1998) Chemical information on tank supernatants, Cs adsorption from tank liquids onto Hanford sediments, and field observations of Cs migration from past tank leaks. PNNL-11495, Pacific Northwest National Laboratory, Richland, WA.

Schramm L. L. and Kwak J. C. T. (1982) Influence of exchangeable cation composition on the size and shape of montmorillonite particles in dilute suspension. Clays Clay Miner. 20, 40-48.

Shainberg I. And Kaiserman A. (1969) Kinetics of the formation and breakdown of Ca-montmorillonite tactoids. Soil Sci. Soc. Am. Proc. 33, 547-551.

Shomer I. and Mingelgrin U. (1978) A direct procedure for determining the number of plates in tactoids of smectites: The Na/Ca-montmorillonite case. Clays Clay Miner. 26, 135-138.

Smith J. T. and Comans R. N. J. (1996) Modelling the diffusive transport and remobilization of ${ }^{137} \mathrm{Cs}$ in sediments: The effects of sorption kinetics and reversibility. Geochim. Cosmochim. Acta 60, 995-1004.

Sposito G. (1981a) Cation exchange in soils: An historical and theoretical perspective. In Chemistry in the Soil Environment, pp. 13-30. American Society of Agronomy, Madison, WI.

Sposito G. (1981b) The Thermodynamics of Soil Solutions. Oxford University Press. New York, pp. 126-154.

Tamura T. and Jacobs D. G. (1960) Structural implications in cesium sorption. Health Phys. 2, 391-393.

Torstenfelt B., Andersson, K., and Allard B. (1982) Sorption of strontium and cesium on rocks and minerals. Chem. Geol. 36, 123-137.

Verburg K., Baveye P., and McBride M. B. (1995) Cation-exchange hysteresis and dynamics of formation and breakdown of montmorillonite quasi-crystals. Soil Sci. Soc. Am. J. 59, 1268-1273.

Wauters J., Elsen A., Cremers A., Konoplev A. V., Bulgakov A. A., and Comans R. N. J. (1996a) Prediction of solid/liquid distribution coefficients of radiocaesium in soils and sediments. Part one: a simplified procedure for the solid phase characterization. Appl. Geochem. 11, 589-594.

Wauters J., Vidal M., Elsen A., and Cremers A. (1996b) Prediction of solid/liquid distribution coefficients of radiocaesium in soils and sediments. Part two: a new procedure for solid phase speciation of radiocaesium. Appl. Geochem. 11, 595-599.

Wauters J., Elsen A., and Cremers A. (1996c) Prediction of solid/liquid distribution coefficients of radiocaesium in soils and sediments. Part three: a quantitative test of a $\mathrm{K}_{\mathrm{D}}$ predictive equation. Appl. Geochem. 11, 601-603.

Weiss C. A. Jr., Kirkpatrick R. J., and Altaner S. P. (1990a) Variations in interlayer cation sites of clay minerals as studied by ${ }^{133} \mathrm{Cs}$ MAS nuclear magnetic resonance spectroscopy. Amer. Mineralogist 75, 970-982.

Weiss C. A. Jr., Kirkpatrick R. J., and Altaner S. P. (1990b) The structural environments of cations adsorbed onto clays: ${ }^{133} \mathrm{Cs}$ variable-temperature MAS NMR spectroscopic study of hectorite. Geochim. Cosmochim. Acta 54, 1655-1669.

Zachara J. M. and Smith S. C. (1994) Edge complexation reactions of cadmium on specimen and soil-derived smectite. Soil Sci. Soc. Am. J. 58, 762-769.

\section{APPENDIX 1}

\section{Two-site Model for $\mathrm{Cs}^{+}$and Monovalent Cation Exchange}

The $\mathrm{Cs}^{+}$exchange reaction of $\mathrm{M}^{+}$-saturated sediments can be expressed as:

$$
C s^{+}+M-\text { sediment }=M^{+}+C s-\text { sediment }
$$

A conditional equilibrium constant $\left(K_{c}\right)$ may be defined for reaction (A1):

$$
K_{c}=\frac{[C s X]\left\{M^{+}\right\}}{[M X]\left\{C s^{+}\right\}}
$$

where $[C s X]$ and $[M X]$ are exchanger phase concentrations and $\left\{M^{+}\right\}$ and $\left\{\mathrm{Cs}^{+}\right\}$are aqueous activities (mol/L) at equilibrium. Because the exchangeable cations are monovalent, their aqueous activity coefficients may be assumed, at first approximation, to be the same. Mole $(N)$ or equivalent $(E)$ fractions can be used as the concentration terms for $[C s X]$ and $[M X]$ in (A2) (Sposito, 1981a,b). We have elected to use equivalent fraction in the multisite model for ease of solution. $K_{c}$ values calculated for monovalent exchange are the same regardless of whether $N$ or $E$ are used as concentration terms, whereas $K_{c}$ values computed for heterovalent exchange are not the same.

In a multisite model, the $C s^{+}$selectivity coefficients on site I and II can be defined as:

$$
K_{c}^{I}\left(C s^{+}-M^{+}\right)=\frac{E_{C s}^{I}}{E_{M}^{I}} \frac{\left[M^{+}\right]}{\left[C s^{+}\right]}
$$




$$
K_{c}^{I I}\left(C s^{+}-M^{+}\right)=\frac{E_{C s}^{I I}\left[M^{+}\right]}{E_{M}^{I I}} \frac{\left.C s^{+}\right]}{\left[C^{+}\right.}
$$

where $K_{c}^{I}\left(C s^{+}-M^{+}\right)$and $K_{c}^{I I}\left(C s^{+}-M^{+}\right)$are $C s^{+}$selectivity coefficients on site I and II, respectively; $E_{C S}^{I}$ and $E_{C s}^{I I}$ are equivalent fractions of $\mathrm{Cs}^{+}$on site I and II; and $E_{M}^{I}$ and $E_{M}^{I I}$ are equivalent fractions of $M^{+}$on site I and II, respectively. These equivalent fractions are related by mass balance equations:

$$
\begin{gathered}
E_{C s}+E_{M}=1 \\
E_{C s}^{I}+E_{M}^{I}=1 \\
E_{C s}^{I I}+E_{M}^{I I}=1 \\
E^{I *} E_{C s}^{I}+E^{I I} * E_{C s}^{I I}=E_{C s}
\end{gathered}
$$

where $E^{I}$ and $E^{I I}$ are equivalent fractions of site I and II on the sediment, and:

$$
E^{I}+E^{I I}=1
$$

The system described by Eqns (A1) through (A9) can be analytically solved as follows:

$$
K_{c}=\frac{K_{C}^{I}\left(C s^{+}-M^{+}\right)}{1-E_{C s}} \frac{a}{2}
$$

where

$$
\begin{gathered}
a=b+\sqrt{b^{2}+4 \frac{K_{c}^{I I}\left(C s^{+}-M^{+}\right)}{K_{c}^{I}\left(C s^{+}-M^{+}\right)} E_{C s}\left(1-E_{C s}\right)} \\
b=E^{I}-E_{C s}+\frac{K_{c}^{I I}\left(C s^{+}-M^{+}\right)}{K_{c}^{I}\left(C s^{+}-M^{+}\right)}\left(1-E^{I}-E_{C s}\right)
\end{gathered}
$$

Equation (A10) contains three parameters: $\mathrm{Cs}^{+}$selectivity coefficients for sites I and II $K_{c}^{I}\left(C s^{+}-M^{+}\right)$and $K_{c}^{I I}\left(C s^{+}-M^{+}\right)$, and the fraction of site $1, E^{I}$, on the sediment. These three parameters can be determined by fitting (A10) to experimental data (e.g., $K_{c}$ vs. $E_{C s}$ ). The fraction of site II, $E^{I I}$, can be determined from (A9).

Because (A10) is nonlinear with respect to the three parameters, the parameter estimation procedure requires initial guesses of their values. The initial guess of the equivalent fraction of site I, $\left(E^{I}\right)$, can be set to the $E_{C s}$ value at the inflection point on an experimental $K_{c}-E_{C s}$ profile. The initial guess of $\mathrm{Cs}^{+}$selectivity coefficient on site I can be estimated from (A2) and (A3) when $E_{C s} \rightarrow 0$, i.e.,

$$
K_{c}=K_{c}^{I}\left(C s^{+}-M^{+}\right) E^{I} \text { or } \log \left(K_{c}^{I}\left(C s^{+}-M^{+}\right)\right)=\log \left(K_{c}\right)-\log \left(E^{I}\right)
$$

The $\mathrm{Cs}^{+}$selectivity coefficient on site II can be estimated from (A2) and (A4) when $E_{C s} \rightarrow 1$, i.e.,

$$
\begin{array}{r}
K_{c}=K_{c}^{I I}\left(C s^{+}-M^{+}\right) /\left(1-E^{I}\right) \text { or } \log \left(K_{c}^{I I}\left(C s^{+}-M^{+}\right)\right) \\
=\log \left(K_{c}\right)+\log \left(1-E^{I}\right)
\end{array}
$$

\section{Multisite Model for $\mathrm{Cs}^{+}$and $\mathrm{Ca}^{2+}$ Exchange}

The $\mathrm{K}_{c}$ for $\mathrm{Cs}^{+}-\mathrm{Ca}^{2+}$ exchange was defined as:

$$
K_{c}=\frac{\left(E_{C s}\right)^{2}}{E_{C a}} \frac{\left\{C a^{2+}\right\}}{\left\{C s^{+}\right\}^{2}}=\frac{\left(E_{C S}\right)^{2}}{1-E_{C s}} \frac{\left\{C a^{2+}\right\}}{\left\{C s^{+}\right\}^{2}}
$$

where $E_{C a}$ is the equivalent fraction of $\mathrm{Ca}^{2+}$ on a sediment and $\left\{\mathrm{Ca}^{2+}\right\}$ is the aqueous activity. We have used aqueous concentration, [ ], as an approximation of activity, recognizing that the activity effects could be large given the divalent cation charge and the high ionic strength (Grant and Fletcher, 1993). Other symbols are defined as before. Similarly, for each site $\mathrm{i}(\mathrm{i}=1,2, \ldots \mathrm{n})$, we can define:

$$
K_{c}^{i}\left(C s^{+}-C a^{2+}\right)=\frac{\left(E_{C s}^{i}\right)^{2}}{1-E_{C s}^{i}} \frac{\left[C a^{2+}\right]}{\left[C s^{+}\right]^{2}}, \mathrm{i}=1,2, \ldots, \mathrm{n}
$$

where $\mathrm{K}_{c}^{i}\left(\mathrm{Cs}^{+}-\mathrm{Ca}^{2+}\right)$ and $E_{C s}^{i}$ are the $C s^{+}$selectivity coefficient and equivalent fraction on site i, respectively. Equations (A13) and (A14) are complemented with the two following mass balance equations,

$$
\begin{gathered}
\sum_{i=1}^{n} E^{i} E_{C s}^{i}=E_{C s} \\
\sum_{i=1}^{n} E^{i}=1
\end{gathered}
$$

The initial guesses for the selectivity coefficients and site fractions of equivalent 1 (the highest selectivity site) and site $\mathrm{n}$ (the lowest selectivity site) can be estimated as described elsewhere (Brouwer et al., 1983). Other initial guesses of the selectivity coefficients are required that range between the highest (site 1) and lowest values (site n). The site fractions range between 0 and 1 , and were constrained by (A16). All of these parameters were adjusted to fit the overall $K_{c}-E_{C s}$ function. The solution algorithm, first computes the ratio, $\left[\mathrm{Ca}^{2+}\right] /\left[\mathrm{Cs}^{+}\right]^{2}$ as a function of $E_{C s}$ from (A14) through (A16) using a modified Powell hybrid algorithm (IMSL, 1991), and then uses (A13) to calculate the $K_{c}-E_{C s}$ curve. The parameters were determined by minimizing the difference between the calculated and measured $K_{c}-E_{C s}$ curves.

\section{APPENDIX 2}

\section{Binary Cs-K Exchange on Site I and Ternary Cs-K-AgTU Exchange on Site II on a K-saturated Sediment}

The following mass action and mass balance equations were used to model $\mathrm{Cs}^{+}$adsorption in presence of $K^{+}$and $\mathrm{AgTU}^{+}$.

$\mathrm{Cs}^{+}-\mathrm{K}^{+}$exchange on site $\mathrm{I}$ :

$$
K_{c}^{I}\left(C s^{+}-K^{+}\right)=\frac{E_{C s}^{I}}{1-E_{C s}^{I}} \frac{\left\{K^{+}\right\}}{\left\{C s^{+}\right\}}
$$

$\mathrm{Cs}^{+}-\mathrm{K}^{+}$exchange on site II:

$$
K_{c}^{I I}\left(C s^{+}-K^{+}\right)=\frac{E_{C s}^{I I}}{E_{K}^{I I}} \frac{\left\{K^{+}\right\}}{\left\{C s^{+}\right\}}
$$

$\mathrm{Cs}^{+}-\mathrm{AgTU}^{+}$exchange on site II:

$$
K_{c}^{I I}\left(C s^{+}-A g T U^{+}\right)=\frac{E_{C s}^{I I}}{E_{A g T u}^{I I}} \frac{\left\{A g T U^{+}\right\}}{\left\{C s^{+}\right\}}
$$

Mass balance for $\mathrm{AgTU}^{+}$:

$$
E_{A g T u}^{I I} E^{I I} C E C \rho+\left[A g T U^{+}\right]=\left[A g T U^{+}\right]_{\text {total }}
$$

Mass balance for $\mathrm{K}^{+}$.

$$
\left(E_{C s}^{I} E^{I}+\left(1-E_{K}^{I I}\right) E^{I I}\right) C E C \rho+\left[K^{+}\right]_{i n t}=\left[K^{+}\right]
$$

Site balance on site II:

$$
E_{C S}^{I I}+E_{K}^{I I}+E_{A g T u}^{I I}=1
$$

where $E_{A g T u}^{I I}$ is the equivalent fraction of $\mathrm{AgTU}^{+}$on site II; CEC (eq/g) is the total sorption capacity determined for $\mathrm{K}$-saturated sediment; $\rho$ is solid density $(\mathrm{g} / \mathrm{L}) ;\left\{\mathrm{AgTU}^{+}\right\}$and $\left[\mathrm{AgTU}^{+}\right]$are aqueous activity and concentration of $\mathrm{AgTU}^{+}$, respectively; and others are as previously defined. All activities were set equal to concentrations. The $\mathrm{Cs}^{+}-\mathrm{K}^{+}$ exchange coefficients and equivalent fractions of site I and site II on the sediment were taken from the binary Cs-K system (Appendix 1). The parameter, $K_{c}^{I I}\left(C^{+}-A g T U^{+}\right)$, was determined using a modified Powell hybrid algorithm (IMSL, 1991) by minimizing the difference between the calculated and measured results in the ternary Cs-K-AgTU system. 